Article

\title{
An Optimal Energy Management Method for the Multi-Energy System with Various Multi-Energy Applications
}

\author{
Yangzi Wang ${ }^{1, *}$, Kai Zhang ${ }^{2}$, Chun Zheng ${ }^{3}$ and Huiyuan Chen ${ }^{3}$ \\ 1 School of Electrical and Electronic Engineering, North China Electric Power University, Beijing 102206, China \\ 2 China Electric Power Research Institute, State Grid Corporation of China, Beijing 100192, China; \\ zhangkai@epri.sgcc.com.cn \\ 3 State Grid Jiangxi Economic Research Institute, Jiangxi Electric Power Corporation, \\ Nanchang 330043, China; jyy_zhengc@jx.sgcc.com.cn (C.Z.); jyy_chenhy@jx.sgcc.com.cn (H.C.) \\ * Correspondence: wyzi@ncepu.edu.cn
}

Received: 5 October 2018; Accepted: 2 November 2018; Published: 16 November 2018

check for updates

\begin{abstract}
As the development of the multi-energy system (MES), various ME applications are deployed. ME applications not only bring advanced functionalities to the MES, but also show great potentials in promoting the operation performance of the MES, especially improving the accommodation of renewable energy sources (RES). However, the realization of these potentials largely relies on the energy management, which shall facilitate the effective function of each ME application and the coordinated collaboration of all the ME applications. Without a comprehensive energy management methodology, ME applications may mutually interfere, which not only hinder the RES utilization, but also may harm the MES operation performance. In this premise, this paper integrates the energy management model of the combined cooling, heat and power plants, power-to-hydrogen/gas-to-power plants, and demand side management model of the EV charging loads into the energy management model of the MES, and proposes an comprehensive optimal day-ahead energy management framework to simultaneously improve the profit, RES utilization rate, and energy saving performance of the MES. To address the proposed optimization model, Elitist Non-dominated Sorting Genetic algorithm II algorithm is employed to heuristically find the Pareto-optimal results. Finally, case studies prove the effectiveness of the proposed methodology.
\end{abstract}

Keywords: energy management; multi-energy application; CCHP; P2H/G2P; EV; demand side management; optimization

\section{Introduction}

Driven by the global warming and fossil fuel depletion, recent years have witnessed the development of the multi-energy system (MES) and the proliferation of the renewable energy sources (RES) [1-5]. RES brings significant energy, environment, and economic benefits. However, due to its intermittency and unpredictability nature, the supply curve of the RES usually fails to match the load profile, which may stress the supply-load balance and threaten the operation of the multi-energy system (MES) [4,5]. Due to this, power system experiences huge amounts of RES curtailment, which causes lots of waste. In the future, the RES penetration will be even higher, thus calling for further intensified and more flexible accommodation mechanisms. Fortunately, with the development of the MES, more and more new cross energy sector ME applications come into being, such as multi-generation application, such as combined cooling, heat, and power (CCHP) plant, power-to-Hydrogen and gas-to-power $(\mathrm{P} 2 \mathrm{H} / \mathrm{G} 2 \mathrm{P})$ plant, and electric vehicle (EV), which not only bring advanced new functionalities to the 
MES, but demonstrate promising potentials in dealing with the poor utilization problem of the RES at the same time [6-14].

$\mathrm{CCHP}$ and $\mathrm{P} 2 \mathrm{H} / \mathrm{G} 2 \mathrm{P}$ are multi-energy generating technologies. As a CCHP plant is supposed to provide cooling, heat, and electricity supply at the same time, it is usually composed of multiple types of energy generating devices, which provide abundant generating options and redundant energy pathways $[7,13,14]$. For instance, heat can be produced by electrical heaters with electricity, or by combustion heat generators with fuel; cooling can be produced by an electric chiller with electricity, or by heat pumps with heat. It suggests that the input and output of CCHP plant can be adjusted with purposes while meeting the ME demands. Reference [6] investigates the impact of the flexible dispatch if the CCHP plants on the operation performance of the integrated electrical and natural gas network, reference [7] investigates its potential in providing real time demand response services. It is this flexibility both regards generation and system dispatch that could be particularly relevant to providing real time ancillary and accommodating the RES. As for P2H/G2P facilities, they can store power into hydrogen through $\mathrm{P} 2 \mathrm{H}$ process, or reversely release the power through G2P process [15]. Its use in accommodating RES is quite intuitive and has been widely studied [9,15-17]. Reference [15] assesses the potential for $\mathrm{P} 2 \mathrm{H}$ to increase wind power dispatchability, and reference [17] explores how to integrate $\mathrm{P} 2 \mathrm{H}$ into power systems for load balancing. In $[10,18]$, the potential of the energy hub equipped with a P2H facility (electrolyzer) and a gas-to-power (G2P) facility (hydrogen gas turbine) is illustrated in accommodating the volatility introduced by a large wind power penetration. With CCHP plants and P2H/G2P plants deployed, the excess of RES outputs can be stored in hydrogen, or/and fuel the electricity-driven devices to supply the ME demands; and when there is a lack of RES outputs, the electricity stored in hydrogen can be released through G2P process, and ME demands could mainly be produced by the fuel-dependent devices.

As a greener means of transportation, EVs have gained increasingly higher market share in recent years, especially in China [19]. It poses a challenge as well as a significant opportunity to the conventional energy system $[20,21]$. Though the EV charging loads risk aggregating the daily peak loads and causing power congestions, appropriate demand side management could encourage the EV customer to delay their charging behavior, which can shift the charging loads from peak hours to off-peak hours [22-25]. In the same way, through scheduling EV charging loads to coincide with periods of strong wind or sun, greater adoption of RES could be achieved. Many studies about the demand side management of EV charging loads have been published [24,25], and economic signal are mostly employed to pre-schedule the EV charging customers' load profile. Reference [23] proposes a decentralized demand side management method based on time-varying prices, to both maximize the aggregators' profits while minimize the consumers' costs. Reference [24] jointly considers the customers' charging requirements and system load profile, proposes a coordinated charging strategy aiming to achieve peak shaving by heuristically setting dynamic time-of-use (TOU) pricing strategy. In [25], the demand response of EV customers to peak-valley pricing is modelled based on price elasticity matrix.

On the one hand, these ME applications bring advanced new functionalities and dispatch resources to the MES and provide possibilities in improving the MES operation, including accommodating more RES. On the other hand, they increase to the total complexity of the operation model of the MES and complicate the entire energy management process. Without a comprehensive energy management model, they may operate in less optimal conditions and add up the cost, or in uncoordinated ways and offset each other, either of which will harm the operation performance of the MES and waste these valuable assets of the MES. Meanwhile, rare cross-sectional researches that include them all are conducted.

On these premises, based on the economic dispatch model of the power system, this paper proposes a novel day-ahead optimal energy management method for the MES with CCHP, P2G, and EV, to simultaneously promote the RES utilization, and the economic and energy-saving performance of the MES. At first, the operation of the CCHP plant, P2G plant, and the demand response model of 
the EV charging load under TOU schemes are modelled respectively. Among them, the modelling of the CCHP devices are based on the concept of "Energy Hub", and the demand response of EV charging load is based on the price elasticity matrix. Then, the model of these three ME applications are integrated in the holistic dispatch model of the MES. Based on the developed model, three objectives are formulated to simultaneously promote the RES utilization rate, and the economic and energy saving performance of the MES. Considering the proposed optimization model is mathematically a multi-objective, mixed integer non-linear model, which cannot be easily solved with classical mathematical techniques, the Elitist Non-dominated Sorting Genetic Algorithm II (NSGA-II) [26] is applied to find Pareto optimal results. The main contributions of this paper are threefold:

1. The energy management of CCHP plant and P2H/G2P plant, and the demand side management of EV charging loads are modelled, and integrated in the energy management model of the MES as dispatch resources.

2. Base on the developed model, a multi-objective optimal energy management problem is proposed to facilitate the cooperation of the ME applications, and simultaneously promote the RES utilization, and the overall economic and energy-saving performance of the MES.

The rest of this paper is organized as follows: Section 2 presents the operation models of the CCHP plants, P2H/G2P plants, and the demand response model of the EV charging loads. Based on the developed models, a multi-objective optimization model for the MES energy management is proposed in Section 3, and tested on cases studies in Section 4. At last, the paper is concluded in Section 5.

\section{Mathematical Modelling of ME Applications}

\subsection{Modelling of CCHP Plant}

A CCHP plant is composed of two sides of ME devices: cogeneration side and cooling power production side.

Cogeneration side:

- Combined heat and power units (CHP) are the core of CCHP plants, which generates both heat and electricity. $\eta_{W}$ and $\eta_{Q}$ are used to describe the ratio of electric power output and heat power output to the fuel thermal energy input respectively.

- Combustion heat generators (CHG) are usually the thermal backup of the CHP. $\eta_{t}$ is used to describe the ratio of heat power output to the fuel thermal energy input.

- Cooling power production side:

- Compression electric refrigeration generators (CERG) are widely used for producing cooling power, both for air conditioning and industrial purposes.

- Electrical heat pumps (EP) are a bimodal CCHP device which can produce heat and cooling power with electric power input.

- Water adsorption refrigeration generators (WARG) are heat-driven cooling power producers.

- Gas absorption refrigerator generators (GARC) are fuelled by natural gas, but are less widespread [27].

Figure 1 shows the inputs and outputs of the ME devices above with their respective performance indicator. $\boldsymbol{F}$ represents the fuel thermal energy, $\boldsymbol{W}$ represents electricity, $Q$ represents heat, and $\boldsymbol{R}$ represents cooling power. Coefficient of performance (COP) is defined as the ratio of cooling power output to the energy input, which is used to represent the performance indicator of cooling production devices. 


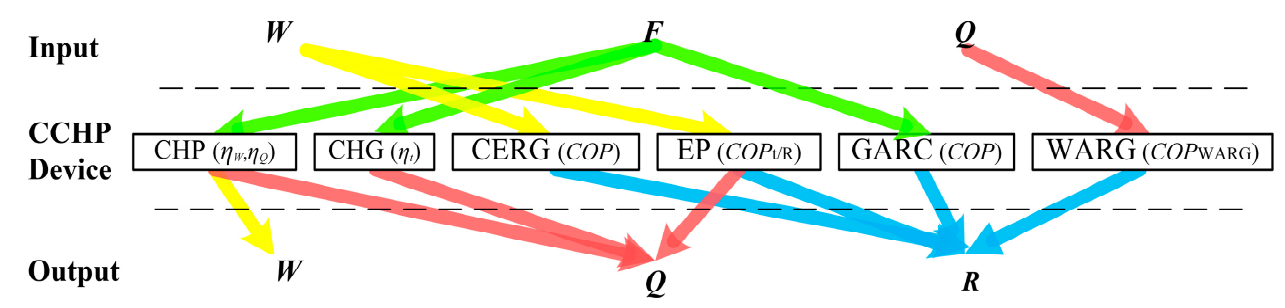

Figure 1. Energy input and output of typical multi-energy (ME) devices. CCHP: combined cooling, heat, and power; $\mathrm{CHP}$ : combined heat and power units; $\mathrm{CHG}$ : combustion heat generators; CERG: compression electric refrigeration generators; EP: electrical heat pumps; GARC: gas absorption refrigerator generators; WARG: water adsorption refrigeration generators; COP: coefficient of performance.

To integrate the operation model of a CCHP plant into the dispatch model of the MES, the model of each component CCHP device should be developed first. For a component CCHP device, $E_{i}=\left[F_{\mathrm{i}}, \mathrm{W}_{\mathrm{i}}, \mathrm{Q}_{\mathrm{i}}, \mathrm{R}_{\mathrm{i}}\right]^{T}$ and $\boldsymbol{E}_{\boldsymbol{o}}=\left[F_{\mathrm{o}}, \mathrm{W}_{\mathrm{o}}, \mathrm{Q}_{\mathrm{o}}, \mathrm{R}_{\mathrm{o}}\right]^{T}$ are used to denote its input and output array respectively, the mapping between energy input $E_{i}$ and output $E_{o}$ is described with the efficiency matrix $\boldsymbol{H}$ as in (1). Each element in $\boldsymbol{H}$ relates one particular input to a certain output with relevant energy conversion efficiency $\eta$, whose two subscript respectively denote the type of energy output and the type of energy input.

$$
\boldsymbol{H}=\left[\begin{array}{cccc}
\eta_{\mathrm{FF}} & \eta_{\mathrm{FW}} & \eta_{\mathrm{FQ}} & \eta_{\mathrm{FR}} \\
\eta_{\mathrm{WF}} & \eta_{\mathrm{WW}} & \eta_{\mathrm{WQ}} & \eta_{\mathrm{WR}} \\
\eta_{\mathrm{QF}} & \eta_{\mathrm{QW}} & \eta_{\mathrm{QQ}} & \eta_{\mathrm{QR}} \\
\eta_{\mathrm{RF}} & \eta_{\mathrm{RW}} & \eta_{\mathrm{RQ}} & \eta_{\mathrm{RR}}
\end{array}\right]
$$

Take the illustrative scheme of a CCHP plant in Figure 2 as an example. It is composed of four CCHP devices, among which are energy pathways: the yellow line represents electric power flow; the green line represents fuel energy flow; the red line represents heat power flow; and the blue line represents cooling power flow. It receives electricity supply $W_{\mathbf{i}}$ from the Electrical Distribution System (EDS) and fuel $F_{\mathbf{i}}$ from the Fuel Distribution System (FDS). Electricity can be both bought from and sold to markets through the EDS. Heat demands can be met by exploiting CHP, CHG, and the EP (heating mode). The cooling demand can be met by using the WARG or/and the EP (cooling mode). Electricity can be drawn from the EDS and/or produced by the CHP (and can be sold back as well). Considering there is no heat storage, extra heat $Q_{\text {Dump }}$ will be dumped. It is the abundant production options and redundant energy pathways that provide possibility for CCHP plant to be part of serving the RES accommodation, and promoting the MES operation.

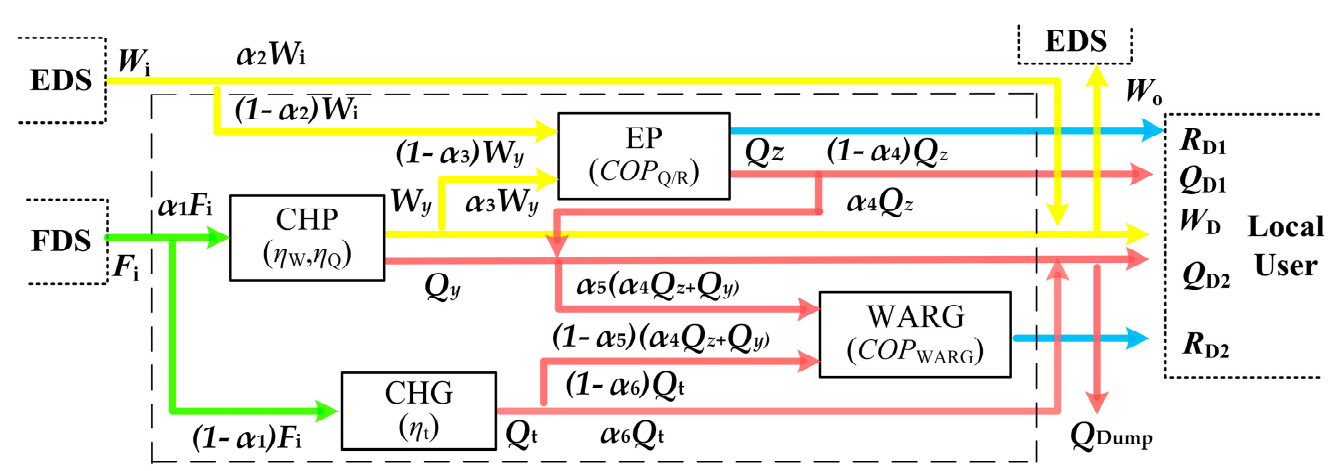

Figure 2. The diagram of a typical combined cooling, heat, and power (CCHP) plant.

In order to model its internal energy flows, energy dispatch factor (EDF) is introduced, which is defined as an array of elements that mark the relative energy dispatch at flow splitting points 
(bifurcations) within the CCHP plant [6,12]. For the CCHP plant in Figure 2, the EDF is defined as $\alpha=\left[\alpha_{1}, \alpha_{2}, \alpha_{3}, \alpha_{4}, \alpha_{5}, \alpha_{6}, \mu_{E P}\right]^{T} . \mu_{\mathrm{EP}}$ denotes the proportion of electricity that is used for the heat production in all the electricity supply of the EP. Then, the input and output relation of the CCHP plant can be described with (2) and (3), where $E_{\mathrm{D}}$ denotes local ME demands, and $E_{\mathrm{Ex}}$ denotes the energy exchange with energy distribution networks:

$$
\begin{gathered}
\boldsymbol{H}=\left(\begin{array}{cccc}
0 & 0 & 0 & 0 \\
\alpha_{3} \alpha_{1} \eta_{\mathrm{W}} & \alpha_{2} & 0 & 0 \\
\eta_{\mathrm{QF}} & \eta_{\mathrm{QW}} & 0 & 0 \\
\eta_{\mathrm{RF}} & \eta_{\mathrm{RW}} & 0 & 0
\end{array}\right) \\
\eta_{\mathrm{QF}}=\eta_{\mathrm{t}} \alpha_{5}\left(1-\alpha_{1}\right)+\alpha_{1} \alpha_{5} \eta_{\mathrm{Q}}+\eta_{\mathrm{W}} \mu_{\mathrm{EP}} C O P_{\mathrm{t}} \alpha_{1}\left(1-\alpha_{3}\right)\left(1-\alpha_{4}\right) \\
\eta_{\mathrm{QW}}=\mu_{\mathrm{EP}} C O P_{\mathrm{Q}}\left(1-\alpha_{2}\right)\left(1-\alpha_{4}\right)+\mu_{\mathrm{EP}} C O P_{\mathrm{Q}}\left(1-\alpha_{2}\right) \alpha_{4} \alpha_{5} \\
\eta_{\mathrm{RW}}=\left(1-\mu_{\mathrm{EP}}\right) C O P_{\mathrm{c}}\left(1-\alpha_{2}\right)+\mu_{\mathrm{EP}} C O P_{\mathrm{Q}} C O P_{\mathrm{WARG}}\left(1-\alpha_{2}\right)\left(1-\alpha_{5}\right) \\
\eta_{\mathrm{RF}}=\left(1-\mu_{\mathrm{EP}}\right) \eta_{\mathrm{W}} C O P_{\mathrm{c}} \alpha_{1}\left(1-\alpha_{3}\right)+\left[\mu_{\mathrm{EP}} \eta_{\mathrm{W}} C O P_{\mathrm{Q}} \alpha_{1}\left(1-\alpha_{3}\right) \alpha_{4}+\eta_{\mathrm{Q}} \alpha_{1}+\eta_{\mathrm{t}}\left(1-\alpha_{1}\right)\left(1-\alpha_{6}\right)\right]\left(1-\alpha_{5}\right) C O P_{\mathrm{WARG}} \\
\boldsymbol{E}_{\mathrm{O}}=\boldsymbol{H} \cdot \boldsymbol{E}_{\mathrm{i}}=\boldsymbol{E}_{\mathrm{D}}+\boldsymbol{E}_{\mathrm{Ex}} .
\end{gathered}
$$

With (2) and (3), the energy management of the CCHP plant can be reflected through a matrix formulism, which makes it easy to be embedded within the optimization model of the MES.

\subsection{Modelling of P2H/G2P Facility}

The schematic of a typical P2H/G2P facility is given in Figure 3. In Figure 3, the area surrounded by dotted line represents $\mathrm{P} 2 \mathrm{H} / \mathrm{G} 2 \mathrm{P}$ plant, which is composed of $\mathrm{P} 2 \mathrm{H}$ (electrolyzer) unit, G2P (hydrogen turbine) unit and hydrogen storage serving as a buffer.

Figure 4 gives the diagram of how RES output variation is accommodated with P2H/G2P plants. When there is a surplus of RES generation, P2G is employed to store them into hydrogen by electrolysis in high-pressure hydrogen tanks or caverns. During periods of low RES generation or high power demand, the stored energy can be converted to power through the G2P process. Therefore, three operation modes are considered in the modelling process: P2H mode, G2P mode, and idling mode. In $\mathrm{P} 2 \mathrm{H}$ mode, the plant acts as an electric demand, while in G2P mode an electrical generator. In the idling mode, the facility is on standby for either P2H or G2P. In (4), I(t) is used to indicate the operation mode of the concerned P2H/G2P plant.

$$
I(t)= \begin{cases}1, & \mathrm{P} 2 \mathrm{H} \\ -1, & \mathrm{G} 2 \mathrm{P} \\ 0, & \text { Other }\end{cases}
$$

Then, the output of the P2H/G2P plant $P_{\mathrm{Hdr}}(t)$ is defined by the linear relationship between the power that charges the hydrogen storage in $\mathrm{P} 2 \mathrm{H}$ mode and the power that discharges it in G2P mode, as in (5) and (6). In (5), $\eta^{\mathrm{G} 2 \mathrm{P}}, \eta^{\mathrm{P} 2 \mathrm{H}}$ are the conversion efficiencies of $\mathrm{G} 2 \mathrm{P}$ and $\mathrm{P} 2 \mathrm{H}$ processes respectively, $P_{\min }^{\mathrm{G} 2 \mathrm{P}}, P_{\max }^{\mathrm{G} 2 \mathrm{P}}$ and $P_{\min }^{\mathrm{P} 2 \mathrm{H}}, P_{\max }^{\mathrm{P} 2 \mathrm{H}}$ are the lower and upper output limits of the corresponding operation modes.

$$
\begin{aligned}
P_{\mathrm{Hdr}}(t)= & P^{\mathrm{G} 2 \mathrm{P}}(t) \cdot \eta^{\mathrm{G} 2 \mathrm{P}}-P^{\mathrm{P} 2 \mathrm{H}}(t) / \eta^{\mathrm{G} 2 \mathrm{P}}, \quad \eta^{\mathrm{G} 2 \mathrm{P}}, \eta^{\mathrm{G} 2 \mathrm{P}} \in[0,1] \\
& P^{\mathrm{G} 2 \mathrm{P}}(t) \in\left[P_{\min }^{\mathrm{G} 22 \mathrm{P}} \cdot I^{\mathrm{G} 2 \mathrm{P}}(t), P_{\max }^{\mathrm{G} 2 \mathrm{P}} \cdot I^{\mathrm{G} 2 \mathrm{P}}(t)\right] \\
& P^{\mathrm{P} 2 \mathrm{H}}(t) \in\left[P_{\min }^{\mathrm{P} 2 \mathrm{H}} \cdot I^{\mathrm{P} 2 \mathrm{H}}(t), P_{\max }^{\mathrm{P} 2 \mathrm{H}} \cdot I^{\mathrm{P} 2 \mathrm{H}}(t)\right]
\end{aligned}
$$

The hydrogen storage level $H^{\text {sto }}(t)$ is constrained by (7)-(9), where (8) ensures that the storage level is sufficient to provide service, and (9) is to avoid end-of-horizon effects by setting the final hydrogen storage level to be close to its initial value. 


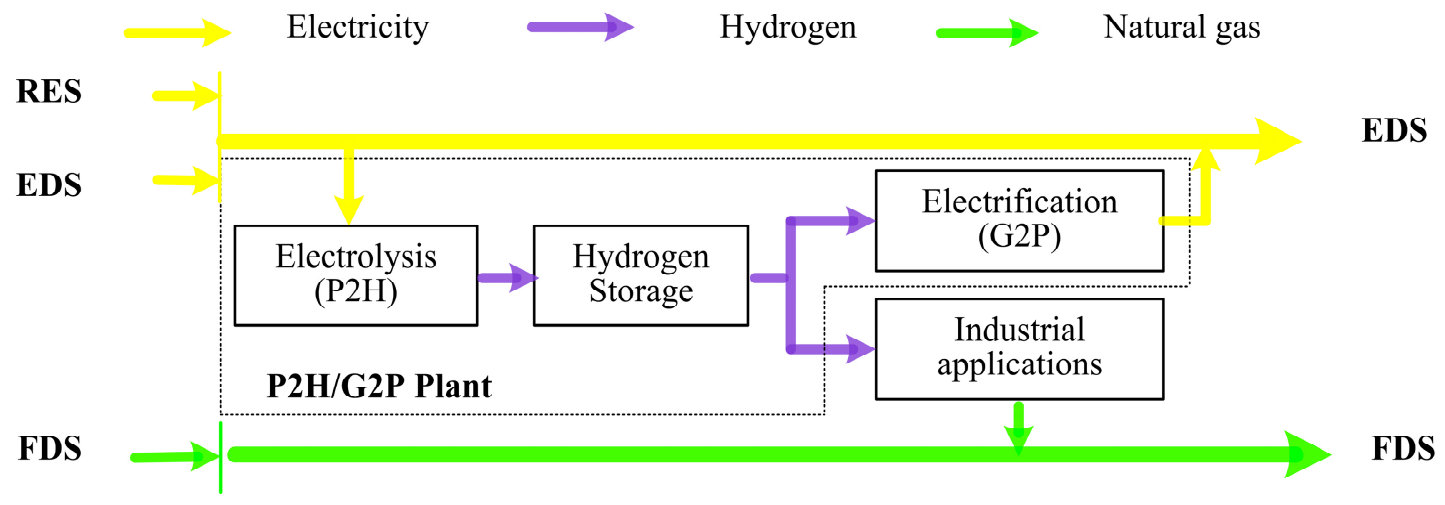

Figure 3. Schematic of P2H/G2P concept. P2H/G2P: Power-to-Hydrogen and Gas-to-Power.

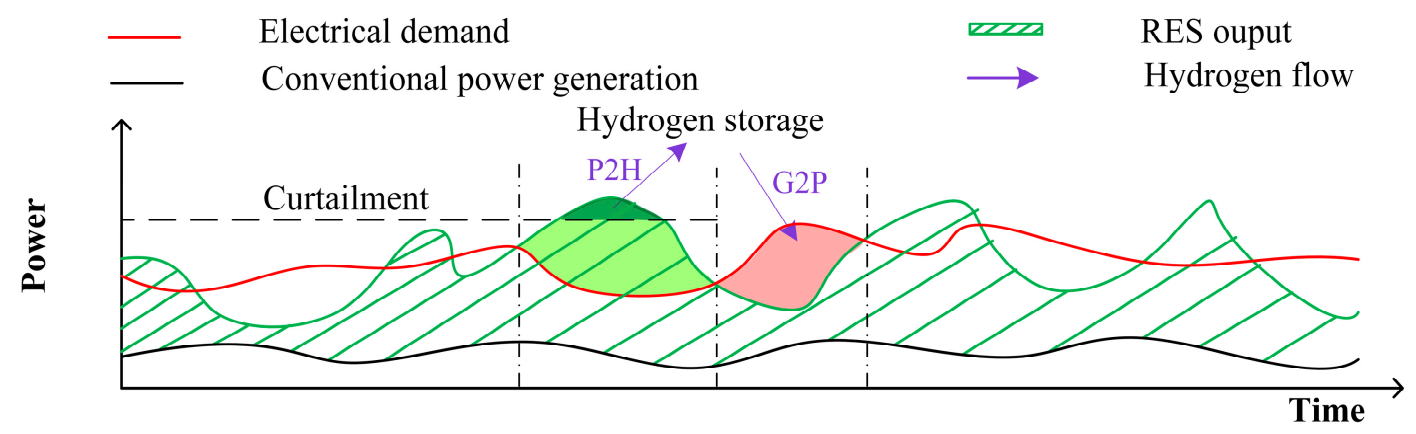

Figure 4. The diagram of accommodating wind power with P2H/G2P.

$$
\begin{gathered}
H^{\text {sto }}(t+1)=H^{\text {sto }}(t)+P^{\mathrm{P} 2 \mathrm{H}}(t) \cdot \Delta t-P^{\mathrm{G} 2 \mathrm{P}}(t) \cdot \Delta t-H^{\text {oth }}(t) \cdot \Delta t \\
H^{\text {sto }}(t) \in\left[H_{\min }^{\text {sto }}, H_{\max }^{\text {sto }}\right] \\
H^{\text {sto }}(n \cdot T) \in\left[H_{0}^{\text {sto }}-\Delta H_{\text {sto }}, H_{0}^{\text {sto }}+\Delta H_{\text {sto }}\right]
\end{gathered}
$$

$H_{\min }^{\text {sto }}$ and $H_{\max }^{\text {sto }}$ are the lower and upper storage limits; $\Delta t$ represents the given time interval; $\Delta H^{\text {sto }}$ is a pre-specified small value; $H^{\text {oth }}$ represents the hydrogen product directly demanded by other energy sectors, which is constrained by $(10)$. In (10) $H_{\max }^{\text {oth }}$ represents the upper limits of the $H^{\text {oth }}$.

$$
H^{\text {oth }}(t) \in\left[0, H_{\max }^{\text {oth }}\right]
$$

\subsection{Demand Response of EV}

In economics, the price-elasticity of demand presents the relative variation of demand caused by the relative variation of the product price, which is the ratio of rate of demand increment over the rate of price increment [28]. The consumer's response to TOU pricing scheme belongs multi-period response, which means the electricity consumptions of most consumers in a period is not only related to the electricity price in the current period, but also related to the electricity prices in adjacent periods $[25,28,29]$. Therefore, the mathematical expression of electricity consumption in a certain period and the price in each period can be expressed as in (11):

$$
\rho_{i}=f\left(D_{\mathrm{ev}, 1}, D_{\mathrm{ev}, 2}, \ldots, D_{\mathrm{ev}, i}, \ldots, D_{\mathrm{ev}, j}, \ldots, D_{\mathrm{ev}, N}\right) \quad i, j \in 1,2, \ldots, N .
$$

In (11), one day is divided into $N$ periods, $D_{\text {ev,i }}$ is the electricity consumption in period $i$, and $\rho_{i}$ is the electricity price in period $i . N$ periods are categorized into three kinds: peak, flat, and valley. 
Around the given equilibrium points in each period, Equation (11) can be linearized with the first order Taylor expansion:

$$
\rho_{i}=\rho_{i 0}+\sum_{j=1}^{n} \frac{\partial \rho_{i}}{\partial D_{e v, j}} \cdot\left(D_{e v, j}-D_{e v, j 0}\right)=\rho_{i 0}+\sum_{j=1}^{n}\left(\frac{\partial \rho_{i}}{\partial D_{e v, j}} \cdot \frac{D_{e v, j 0}}{\rho_{i 0}}\right) \cdot \frac{\rho_{i 0}}{D_{e v, j 0}} \cdot\left(D_{e v, j}-D_{e v, j 0}\right) \quad i, j=1,2, \ldots \ldots N
$$

Define the self-elasticity coefficient $\varepsilon_{i i}$ and cross-elasticity coefficient $\varepsilon_{i j}$ as in (13):

$$
\varepsilon_{i i}=\frac{\partial \rho_{i} / \rho_{i 0}}{\partial D_{\mathrm{ev}, i} / D_{\mathrm{ev}, i 0}} \quad, \quad \varepsilon_{i j}=\frac{\partial \rho_{i} / \rho_{i 0}}{\partial D_{\mathrm{ev}, j} / D_{\mathrm{ev}, j 0}} .
$$

So the price-elasticity matrix of demand can be derived as in (14):

$$
\left[\begin{array}{c}
\Delta \rho_{1} / \rho_{10} \\
\Delta \rho_{2} / \rho_{20} \\
\ldots \\
\Delta \rho_{n} / \rho_{n}
\end{array}\right]=\left[\begin{array}{cccc}
\varepsilon_{11} & \varepsilon_{12} & \ldots & \varepsilon_{1 n} \\
\varepsilon_{21} & \varepsilon_{22} & \ldots & \varepsilon_{2 n} \\
& \ldots & \\
\varepsilon_{n 1} & \varepsilon_{n 2} & \ldots & \varepsilon_{n n}
\end{array}\right]\left[\begin{array}{c}
\Delta D_{\mathrm{ev}, 1} / D_{\mathrm{ev}, 10} \\
\Delta D_{\mathrm{ev}, 2} / D_{\mathrm{ev}, 20} \\
\ldots \\
\Delta D_{\mathrm{ev}, n} / D_{\mathrm{ev}, n}
\end{array}\right]
$$

where $\Delta D_{\mathrm{ev}, i}$ denotes the electricity consumption increment during period $i$, and $\Delta \rho_{i}$ the price increment during period $j$.

According to (12), the linearized relations between electricity consumption and price around respective equilibrium points in peak, flat and, valley periods can be described with (15)-(17), where $D_{\mathrm{ev}, \mathrm{h}}, D_{\mathrm{ev}, \mathrm{f}}$, and $D_{\mathrm{ev}, \mathrm{v}}$ are the electricity consumption during peak period, flat period, and valley period respectively; $\rho_{\mathrm{h}}, \rho_{\mathrm{f}}$, and $\rho_{\mathrm{v}}$ are the electricity price during peak period, flat period, and valley period respectively. $k_{\mathrm{h}}$ and $b_{\mathrm{h}}, k_{\mathrm{f}}$ and $b_{\mathrm{f}}$, and $k_{\mathrm{v}}$ and $b_{\mathrm{v}}$ define the linearized relations around the equilibrium points between the electricity consumption and price during each period. $\Omega_{\mathrm{H}}, \Omega_{\mathrm{F}}$, and $\Omega_{\mathrm{V}}$ denote the peak, flat, and valley periods sets respectively.

$$
\begin{array}{cc}
\rho_{\mathrm{h}}\left(t_{i}\right)=-k_{\mathrm{h}} \cdot D_{\mathrm{ev}, \mathrm{h}}\left(t_{i}\right)+b_{\mathrm{h}}, & i \in \Omega_{\mathrm{H}} \\
\rho_{\mathrm{f}}\left(t_{j}\right)=-k_{\mathrm{f}} \cdot D_{\mathrm{ev}, \mathrm{f}}\left(t_{j}\right)+b_{\mathrm{f}}, \quad j \in \Omega_{\mathrm{F}} \\
\rho_{\mathrm{v}}\left(t_{k}\right)=-k_{\mathrm{v}} \cdot D_{\mathrm{ev}, \mathrm{v}}\left(t_{k}\right)+b_{\mathrm{v}}, \quad k \in \Omega_{\mathrm{V}}
\end{array}
$$

With (15), the self-elasticity defined in (13) can be rewritten into (16).

$$
\varepsilon_{i i}=\frac{-k_{i} \cdot D_{\mathrm{ev}, i}}{-k_{i} \cdot D_{\mathrm{ev}, i}+b_{i}}, i \in \Omega_{\mathrm{H}}, \Omega_{\mathrm{F}} \text { or } \Omega_{V}
$$

Assume the total daily electricity consumption remains the same with or without TOU pricing scheme, then (17) can be obtained.

$$
\sum_{i=1}^{N} \rho_{i}=\rho_{i}+\sum_{\substack{i \neq j \\ j=1}}^{N}-k_{j} D_{e v, j}+b_{j}=\text { const. }, \quad i, j, o \in \Omega_{\mathrm{H}}, \Omega_{\mathrm{F}} \text { or } \Omega_{V}
$$

Take the partial derivatives concerning $D_{\mathrm{ev}, j}$ for both sides of the (17), we can get:

$$
0=\frac{\partial \rho_{i}}{\partial D_{\mathrm{ev}, j}}-k_{j}, \quad i, j \in \Omega_{\mathrm{H}}, \Omega_{\mathrm{F}} \text { or } \Omega_{V}
$$

With (18), the cross-elasticity coefficient $\varepsilon_{i j}$ can be obtained as in (19):

$$
\varepsilon_{i j}=\frac{\partial \rho_{i} / \rho_{i 0}}{\partial D_{\mathrm{ev}, j} / D_{\mathrm{ev}, j 0}}=\frac{-k_{j} \cdot D_{\mathrm{ev}, j}}{-k_{i} \cdot D_{\mathrm{ev}, i}+b_{i}}, \quad i \neq j \& i, j \in \Omega_{\mathrm{H}}, \Omega_{\mathrm{F}} \text { or } \Omega_{V} .
$$


With (14), (16), and (19), the daily electricity consumption under the TOU pricing scheme can be obtained as in (20), Where $\rho_{\mathrm{TOU}}$ and $\rho_{0}$ denote the TOU price and the base price.

$$
\rho_{\mathrm{TOU}}=\rho_{0}+\operatorname{diag}\left\{\rho_{1}, \rho_{2}, \ldots \rho_{N}\right\} \cdot\left[\begin{array}{cccc}
\varepsilon_{11} & \varepsilon_{12} & \ldots & \varepsilon_{1 N} \\
\varepsilon_{21} & \varepsilon_{22} & \ldots & \varepsilon_{2 N} \\
& \ldots & \\
\varepsilon_{N 1} & \varepsilon_{N 2} & \ldots & \varepsilon_{N N}
\end{array}\right] \cdot\left[\begin{array}{c}
\Delta D_{\mathrm{ev}, 1} / D_{\mathrm{ev}, 10} \\
\Delta D_{\mathrm{ev}, 2} / D_{\mathrm{ev}, 20} \\
\ldots \\
\Delta D_{\mathrm{ev}, N} / D_{\mathrm{ev}, N 0}
\end{array}\right]
$$

\section{Energy Management Framework}

Based on the model of the three ME applications that are developed in Section 2, a novel optimal energy management framework for the ME system with ME applications is proposed, and its mathematical model is given in detail in this section. The decision variables vector $V$ is defined as in (21). In (21), $\boldsymbol{P}_{\mathrm{G}}$ and $\boldsymbol{P}_{\mathrm{Hdr}}$ are the output arrays for generators and P2H (G2P) plants respectively, $p$ is the daily charging price array of EVs, and $\alpha$ is the EDF vector for CCHP plants.

$$
\boldsymbol{V}=\left[\begin{array}{llll}
\boldsymbol{P}_{\mathrm{G}}, & \boldsymbol{P}_{\mathrm{Hdr}}, & \boldsymbol{\rho}_{\mathrm{TOU}}, & \alpha
\end{array}\right]^{T}
$$

The objective function comprises of three individual objectives: $F_{1}, F_{2}$, and $F_{3} . F_{1}$ is modeled as the profits of the MES, which is defined as the total revenue through selling electricity minus the generation cost:

$$
\begin{aligned}
& F_{1}=\underset{t a x}{\max } \sum_{t=1}^{N}\left\{\sum_{i \in \Omega_{\mathrm{B}}} \rho_{\mathrm{O}}^{\mathrm{EDS}}(t) \cdot D_{i}(t)+\sum_{i \in \Omega_{\mathrm{Chr}}} \rho_{\mathrm{TOU}}^{\mathrm{EDS}}(t) \cdot P_{\mathrm{Chr}, i}(t)-\sum_{j \in \Omega_{\mathrm{G}}} \rho_{\mathrm{G}}^{\mathrm{FDS}} \cdot\left(a_{j}+b_{j} \cdot P_{\mathrm{G}, j}(t)+c_{j} \cdot P_{\mathrm{G}, j}^{2}(t)\right)\right. \\
& -\sum_{k \in \Omega_{\mathrm{Hdr}}}|I(t)| \cdot\left[\frac{(I(t)+1)}{2} \cdot\left(b_{\mathrm{P} 2 \mathrm{H}, k} \cdot P_{\mathrm{P} 2 \mathrm{H}, k}(t)+c_{\mathrm{P} 2 \mathrm{H}, k}\right)\right. \\
& \left.+\frac{(I(t)-1)}{2} \cdot\left(a_{\mathrm{G} 2 \mathrm{P}, k} \cdot P_{\mathrm{G} 2 \mathrm{P}, k}^{2}(t)+b_{\mathrm{G} 2 \mathrm{P}, k} \cdot P_{\mathrm{G} 2 \mathrm{P}, k}(t)+c_{\mathrm{G} 2 \mathrm{P}, k}\right)\right] \\
& \left.-\sum_{m \in \Omega_{\mathrm{CCHP}}} \rho_{\mathrm{CCHP}}^{\mathrm{FDS}} \cdot F_{\mathrm{CCHP}, m}(t)\right\}
\end{aligned}
$$

In (22), $\Omega_{\mathrm{B}}, \Omega_{\mathrm{Chr}}, \Omega_{\mathrm{G}}, \Omega_{\mathrm{Hdr}}$, and $\Omega_{\mathrm{CCHP}}$ are the buses set, generators set, EV charging facilities set, $\mathrm{P} 2 \mathrm{H} / \mathrm{G} 2 \mathrm{P}$ plants set, and CCHP plants set; $P_{\mathrm{G}}$ is the output of the generator, $P_{\mathrm{P} 2 \mathrm{H}}$ and $P_{\mathrm{G} 2 \mathrm{P}}$ are the output of $\mathrm{P} 2 \mathrm{H} / \mathrm{G} 2 \mathrm{P}$ plant in $\mathrm{P} 2 \mathrm{H}$ and G2P process, respectively, and $a_{j}, b_{j}, c_{j}, b_{\mathrm{P} 2 \mathrm{H}}, c_{\mathrm{P} 2 \mathrm{H}}, a_{\mathrm{G} 2 \mathrm{P}}$, $b_{\mathrm{G} 2 \mathrm{P}}$, and $c_{\mathrm{G} 2 \mathrm{P}}$ are their corresponding consumption characteristic factors; $I$ is the state indication of $\mathrm{P} 2 \mathrm{H} / \mathrm{G} 2 \mathrm{P}$ plant; $D$ is the electric load and $P_{\mathrm{Chr}}$ is the EV charging load; $\rho_{\mathrm{O}}^{\mathrm{EDS}}$ is the hourly selling price of electricity, $\rho_{\mathrm{TOU}}^{\mathrm{EDS}}$ is the hourly price for EV charging, $\rho_{\mathrm{G}}^{\mathrm{FDS}}$ and $\rho_{\mathrm{CCHP}}^{\mathrm{FDS}}$ are the fuel price for power production, and heat, cooling power production.

$F_{2}$ is modelled as in (23) to describe the daily utilization rate of the renewable energy outputs:

$$
F_{2}=\max \left(\frac{\sum_{i \in \Omega_{\mathrm{R}}} \sum_{t=1}^{N} P_{\mathrm{R}, i}(t)}{\sum_{i \in \Omega_{\mathrm{R}}} \sum_{t=1}^{N} P_{R \max , i}(t)}\right) .
$$

In (23), $\Omega_{R}$ denotes the RES generating units set, $P_{R}$ and $P_{R_{-} \max }$ denote the outputs and maximal outputs of the RES.

$F_{3}$ is modelled to describe the energy saving performance of the concerned MES [6]. In (24), $W_{\mathrm{CCHP}}, Q_{\mathrm{CCHP}}$, and $R_{\mathrm{CCHP}}$ are the electricity, heat, and cooling output of CCHP plants, $\eta_{F}$ is the thermal energy rate of the fuel injection. 


$$
\begin{array}{cc}
F_{3}= & \max \left\{1-\frac{F}{\mathrm{~W} / \eta_{\mathrm{e}}^{\mathrm{SP}}+Q / \eta_{\mathrm{t}}^{\mathrm{SP}}+R /\left(\eta_{\mathrm{e}}^{\mathrm{SP}} \cdot \mathrm{COP} P \mathrm{SP}\right)}\right\} \\
F= & \sum_{i \in \Omega_{\mathrm{G}}} \eta_{F} \cdot\left(a_{i}+b_{i} \cdot P_{\mathrm{G}, i}+c_{i} \cdot P_{\mathrm{G}, i}^{2}\right)+\sum_{m \in \Omega_{M E}} F_{\mathrm{CCHP}, \mathrm{m}} \\
W= & \sum_{i \in \Omega_{\mathrm{G}}} P_{\mathrm{G}, i}+\sum_{j \in \Omega_{H D R O}}|I| \cdot\left[\frac{(I-1)}{2} \cdot P_{\mathrm{G} 2 \mathrm{P}, j}-\frac{(I+1)}{2} \cdot P_{\mathrm{P} 2 \mathrm{H}, j}\right]+ \\
& +\sum_{k \in \Omega_{R}} P_{R, k}+\sum_{m \in \Omega_{\mathrm{CCHP}}} W_{C C H P, \mathrm{~m}} \\
Q= & \sum_{m \in \Omega_{\mathrm{CCHP}}} Q_{\mathrm{CCHP}, \mathrm{m}}, R=\sum_{m \in \Omega_{\mathrm{C} C H P}} R_{C C H P, \mathrm{~m}}
\end{array}
$$

The constraints part are composed of electrical network constraints and ME applications constraints.

$$
\begin{aligned}
& P_{G i}-P_{L i}-U_{i} \sum_{j=1}^{n} U_{j}\left(G_{i j} \cos \theta_{i j}+B_{i j} \sin \theta_{i j}\right)=0 \quad\left(i, j \in \Omega_{\mathrm{B}}\right) \\
& Q_{G i}-Q_{L i}-U_{i} \sum_{j=1}^{n} U_{j}\left(G_{i j} \sin \theta_{i j}-B_{i j} \cos \theta_{i j}\right)=0 \quad\left(i, j \in \Omega_{\mathrm{B}}\right) \\
& \underline{P_{G i}} \leq P_{G i} \leq \overline{P_{G i}}, \underline{Q_{G i}} \leq Q_{G i} \leq \overline{Q_{G i}} \quad\left(i \in \Omega_{G}\right) \\
& \left|S_{i j}\right| \leq \overline{S_{i j}} \quad\left(i, j \in \Omega_{\mathrm{B}}\right) \\
& \underline{U_{i}} \leq U_{i} \leq \overline{U_{i}} \quad\left(i \in \Omega_{\mathrm{B}}\right)
\end{aligned}
$$

Equations (25)-(27) are electrical network constraints. Equation (25) represents the active and reactive power balance for each bus. Equation (26) represents the output limits of generators. Equation (27) represents the operational limits on the apparent power and the steady-state voltage magnitude. $P_{G i}$ and $Q_{G i}$ denote the active and reactive power outputs, $P_{L i}$ and $Q_{L i}$ denote the active and reactive power loads, $U_{i}$ denotes the voltage magnitude of Bus $i$ and $\theta_{i j}$ denotes the voltage angle gap between Bus $i$ and Bus $j, G_{i j}$, and $B_{i j}$ denote the real and imaginary parts of the $i$ th row the $j$ th column element in the nodal admittance matrix. $S_{i j}$ denotes the apparent power between bus $i$ and bus $j$.

$$
\begin{gathered}
\underline{E_{\mathrm{i}, x}} \leq E_{\mathrm{i}, x} \leq \overline{E_{\mathrm{i}, x}} \quad\left(x \in m, m \in \Omega_{\mathrm{CCHP}}\right) \\
\frac{E_{\mathrm{O}, x}}{\leq} H_{x} \cdot E_{\mathrm{i}, x} \leq \overline{E_{\mathrm{o}, x}} \quad\left(x \in m, m \in \Omega_{\mathrm{CCHP}}\right) \\
H^{m} \cdot E_{\mathrm{i}}^{m}=E_{\mathrm{D}}^{m}+E_{\mathrm{Ex}}^{m} \quad\left(m \in \Omega_{\mathrm{CCHP}}\right)
\end{gathered}
$$

Equations (28)-(30) are the CCHP plants constraints. In (28) and (29), $\overline{E_{\mathrm{i}, x}}$ and $E_{\mathrm{i}, x}$ are the maximum input and minimum input of ME device $x$ in the CCHP plant $m, \overline{E_{0, x}}$ and $E_{0, x}$ its maximum output and minimum output. In (30), $E_{\mathrm{i}}^{m}$ and $E_{\mathrm{D}}^{m}$ are the ME input of the CCHP plant $m$ and local ME demands, $E_{\mathrm{Ex}}^{m}$ is the ME exchange between the CCHP plant $m$ and the external energy distribution networks.

The constraints of $\mathrm{P} 2 \mathrm{H} / \mathrm{H} 2 \mathrm{P}$ plants are defined in Section 2.2 as in (4)-(10).

$$
\begin{gathered}
\rho_{\mathrm{TOU}} \leq \rho_{\mathrm{TOU}}^{\mathrm{EDS}}(t) \leq \overline{\rho_{\mathrm{TOU}}} \quad(t=1,2, \ldots, N) \\
0 \leq P_{\mathrm{Chr}, i}(t) \leq \overline{P_{\mathrm{Chr}, i}} \quad\left(i \in \Omega_{\mathrm{Chr}}, t=1,2, \ldots, N\right)
\end{gathered}
$$

Equations (31) and (32) are the EV charging constraints. In (31), $\rho_{\mathrm{TOU}}$ and $\overline{\rho_{\mathrm{TOU}}}$ are the minimum and maximum price of the EV charging price. In (32), $\overline{P_{\mathrm{Chr}, i}}$ is the maximum EV charging load at the EV charging facility $i$.

The proposed energy management model is mathematically a multi-objective, mixed integer non-linear optimization model, and NSGAII is employed to address it. The computation process shown in Figure 5 can be summarized as follows. 


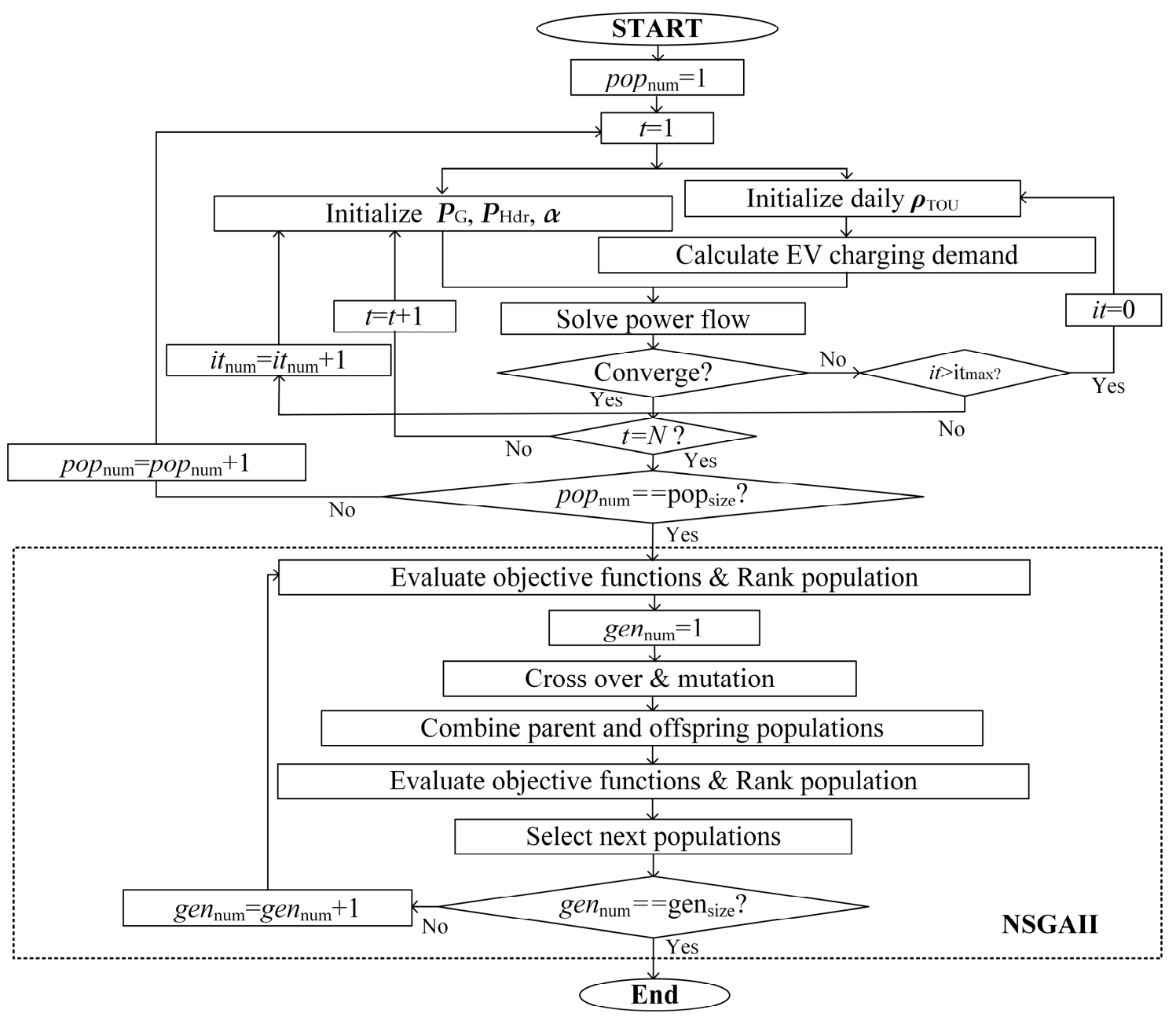

Figure 5. Computation flow chart.

STEP 1: Initialize the population number pop $_{\text {num, }}$ generation number $g{ }_{\text {num }}$, and starting time $t$, assuming a day is divided into $N$ periods.

STEP 2: If pop $_{\text {num }}=$ pop $_{\text {size }}$, go to Step 5; if not, initialize daily EV charging price $\rho_{\mathrm{TOU}}$, and calculate EV charging load under $\rho_{\text {TOU }}$.

STEP 3: Initialize outputs of generators $\boldsymbol{P}_{\mathrm{G}}$, outputs of $\mathrm{P} 2 \mathrm{H} / \mathrm{G} 2 \mathrm{P}$ plants $\boldsymbol{P}_{\mathrm{P} 2 \mathrm{G}}$, and EDF of CCHP plants $\alpha$.

STEP 4: Solve power flow. If the power flow results converge, go to STEP 5; if not converge, and iteration times it $<i t_{\max }$, reinitialize $\boldsymbol{P}_{\mathrm{G}}, \boldsymbol{P}_{\mathrm{P} 2 \mathrm{G}}$ and $\boldsymbol{\alpha}$, it $=i t+1$, go to STEP 3; Otherwise, reinitialize $\rho_{\mathrm{TOU}}$, it $=0$, go to STEP 2.

STEP 5: if $t<\mathrm{N}, t=t+1$, go to STEP 6; else, pop $_{\text {num }}=p_{\text {op }}$ num +1 , go to STEP 2;

STEP 6: Evaluate and rank each population.

STEP 7: After crossing over and mutation process, offspring population and parent population are evaluated, ranked and then selected.

STEP 8: if gen $_{\text {num }}=$ gen $_{\text {size }}$, the remaining results consist of the Pareto-optimal results; if not, $g e n_{\text {num }}=g e n_{\text {num }}+1$, go to STEP 6 .

\section{Simulation and Results}

Two case studies consisting of a six-bus (Case A) [30] and the modified IEEE 39-bus system (Case B) are performed in this section. Case $\mathrm{A}$ is designed to first demonstrate the accommodating effects of the CCHP utilizations, P2H/G2P utilizations, and demand response of EV charging loads respectively, 
and then demonstrate the performance loss when no energy management strategies are used. Case B is designed to show the effectiveness of the proposed optimal energy management method.

\subsection{Case A}

The six-bus system shown in Figure 6 is studied over the 24-h of operation. It includes three conventional generators: G1, G2, and G3. A CCHP plant, a P2H/G2P plant, a wind turbine, and an EV charging unit are all located on Bus 4. Parameters of them are listed in Tables 1-3. Consider the maximum and minimum capacity of the hydrogen storage are $200 \mathrm{MWh}$ and $40 \mathrm{MWh}$ respectively, and its initial storage level is $80 \mathrm{MWh}$ [12]. Assume the efficiency for P2H and G2P processes are $80 \%$ and $40 \%$, respectively. The hourly electric demand, EV charging demand, forecasted wind power (with $200 \mathrm{MW}$ installed capacity), and ME demands over the 24-h horizon are listed in Figure 7. The gas price is $3.71 \$ / \mathrm{MBtu}$ for the CCHP production, and the selling price of electricity is 51.22 \$/MWh (23:00-7:00), 73.27 \$/MWh (10:00-17:00 and 21:00-23:00), and 85.04 \$/MWh (9:00-10:00 and 18:00-20:00). Consider the separate generation efficiencies are $\eta_{e}^{S P}=0.4, \eta_{t}^{S P}=0.9$, and $\mathrm{COP}^{\mathrm{SP}}=3.5$ [16]. The parameters of the NSGAII algorithm are set as follows: the population size pop $_{\text {size }}=100$, the evolution time gen $n_{\text {size }}=1000$, and the crossover and mutation probabilities are 0.8 and 0.2 , respectively.

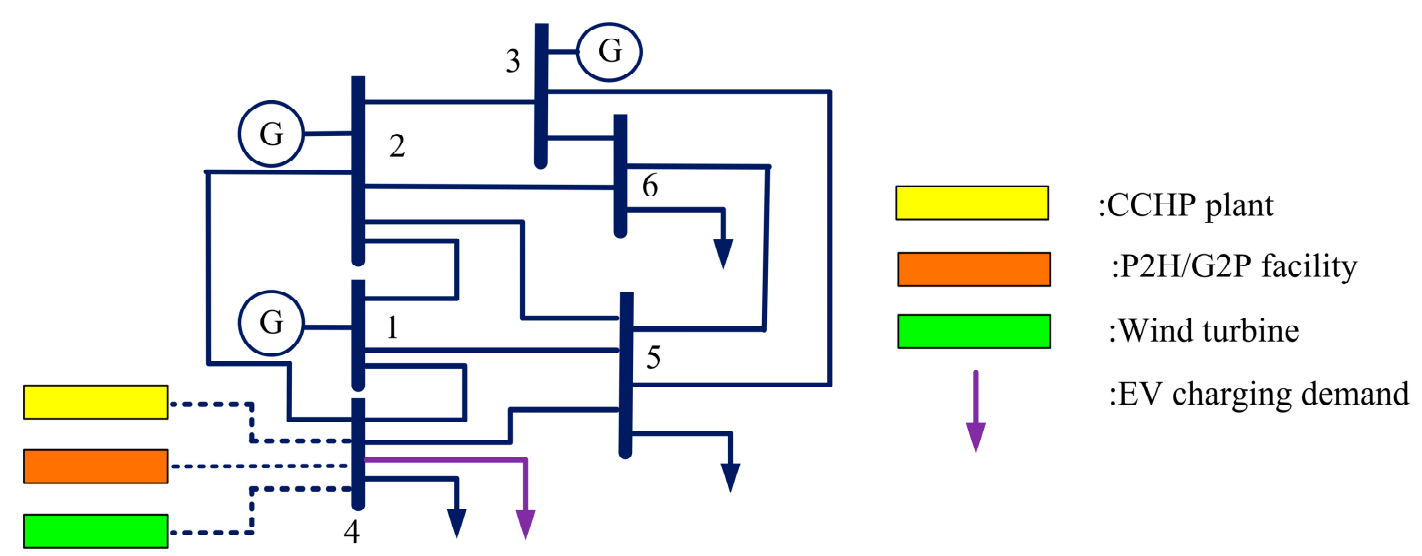

Figure 6. Example six-bus power system. EV: Electric Vehicle.

Table 1. Generation unit characteristics 1.

\begin{tabular}{cccc}
\hline Unit & $\mathbf{a}\left(\mathbf{M B t u} / \mathbf{M W}^{\mathbf{2}} \mathbf{h}\right)$ & $\mathbf{b} \mathbf{( M B t u} / \mathbf{M W h})$ & $\mathbf{c}(\mathbf{M B t u})$ \\
\hline G1 & 0.0004 & 13.5 & 176.9 \\
G2 & 0.001 & 32.6 & 129.9 \\
G3 & 0.006 & 17.6 & 137.4 \\
P2H & - & 12.5 & 141 \\
G2P & 0.0065 & 19.6 & 141.4 \\
\hline
\end{tabular}

Table 2. Generation unit characteristics 1.

\begin{tabular}{cccccc}
\hline Unit & $\mathbf{P}_{\max }(\mathbf{M W})$ & $\mathbf{P}_{\min }(\mathbf{M W})$ & $\boldsymbol{\gamma}$ (CNY/MBtu) & $\mathbf{T}^{\text {on }} \mathbf{( h )}$ & $\mathbf{T}^{\text {off }} \mathbf{( h )}$ \\
\hline G1 & 700 & 100 & 8.1049 & 1 & 1 \\
G2 & 250 & 30 & 8.0997 & 2 & 3 \\
G3 & 200 & 10 & 8.1003 & 1 & 1 \\
P2H & 40 & 10 & 0.065 & 1 & 1 \\
G2P & 20 & 10 & 8.125 & 1 & 1 \\
\hline
\end{tabular}


Table 3. Generation unit characteristics 2.

\begin{tabular}{ccc}
\hline ME Device & Efficiency & Capacity \\
\hline CHP & $\eta_{W}=36 \%$ & $300 \mathrm{MW}$ \\
CHG & $\eta_{Q}=43 \%$ & $650 \mathrm{MW}$ \\
EHP & $\eta_{t}^{S P}=90 \%$ & $150 \mathrm{MW}$ \\
WARG & COP $=3.5$ & $800 \mathrm{MW}$ \\
\hline
\end{tabular}

In order to show their respective potentials in accommodating the RES, six cases are designed as in Table 4. For Case A, only RES utilization rate is considered as the objective of the optimization problem. Among the six cases, Case 1 is the control case-a six-bus with a wind turbine. The hourly dispatch results for Case 1-6 are given in Figures 8-13 respectively. In Figures 9-11, (a) shows the outputs of generators, and (b) shows the dispatch results of each ME application. Compare Figures 8 and 11, it could be easily noticed that the EV charging load under TOU pricing schemes could effectively enlarge the yellow area-improve the wind power utilization.

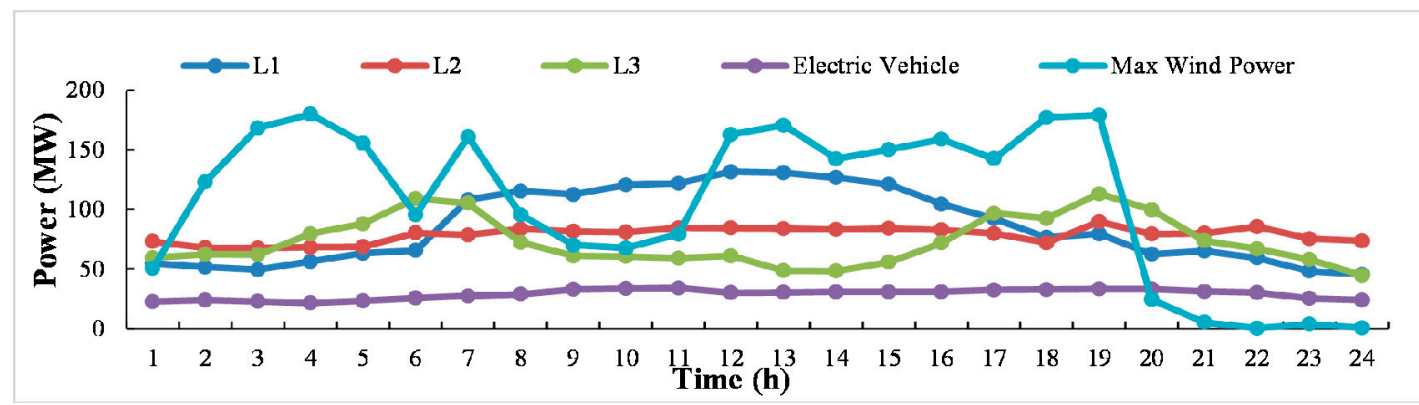

(a)

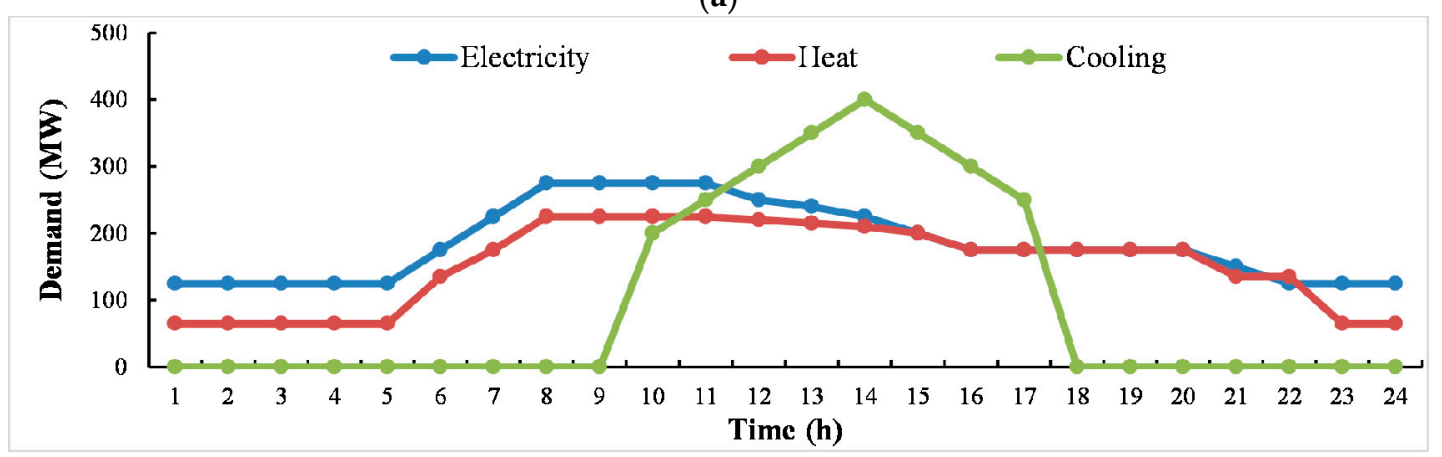

(b)

Figure 7. Hourly forecasted wind power and demand distribution. (a) Forecasted wind power and electric demand. (b) Multi-energy demand.

Table 4. Case design.

\begin{tabular}{ccccc}
\hline Case Num. & Wind Power & CCHP & P2H/G2P & Demand Response of EVs \\
\hline 1 & $\sqrt{ }$ & $\times$ & $\times$ & $\times$ \\
2 & $\sqrt{ }$ & $\sqrt{ }$ & $\times$ & $\times$ \\
3 & $\sqrt{ }$ & $\times$ & $\sqrt{ }$ & $\times$ \\
4 & $\sqrt{ }$ & $\times$ & $\times$ & $\sqrt{ }$ \\
$5 \& 6$ & $\sqrt{ }$ & $\sqrt{ }$ & $\sqrt{ }$ & $\sqrt{ }$ \\
\hline
\end{tabular}




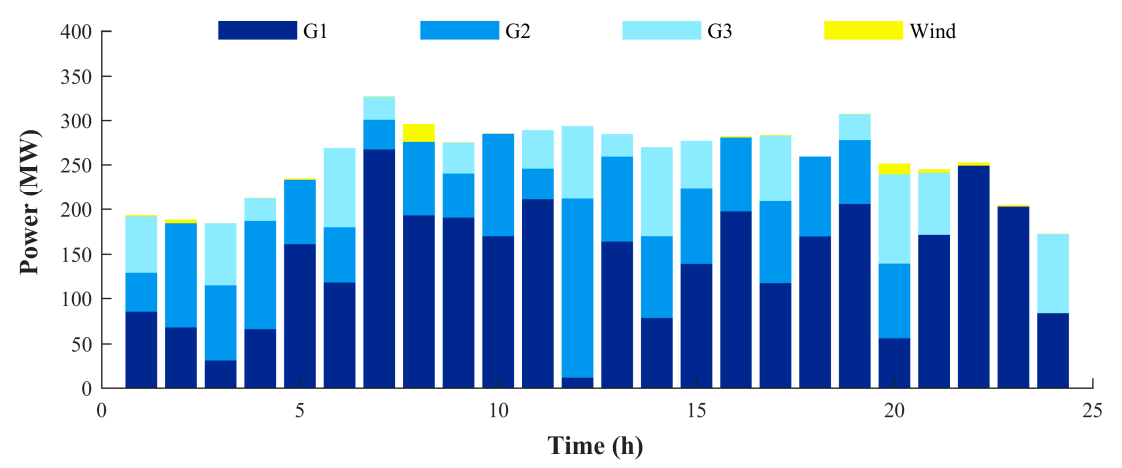

Figure 8. Dispatch result in Case 1.

In Figure 9, when the wind power is abundant, the generation of the ME demands mainly depends on the free wind power. For instance, in Figure $9 \mathrm{~b}, \mathbf{W}_{\mathrm{i}}$ peaks during 8:00-21:00. When the forecasted wind power slumps at 20:00, the production of the CCHP plant turns to rely on the natural gas input, especially when some generators are offline. For instance, at 23:00, only G1 is online, and at 24:00, 1:00, only G1 and G3 are online. In these periods, CCHP plant generates more electricity on purpose to feedback the electric networks.

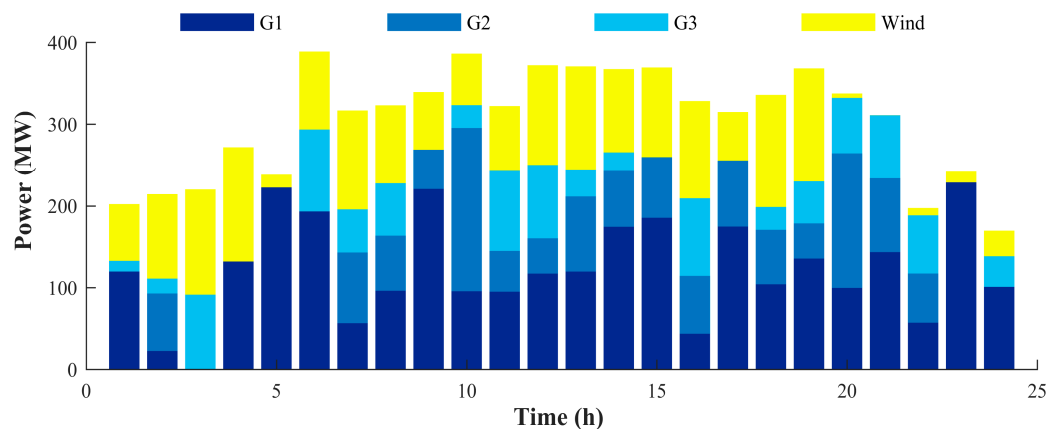

(a)

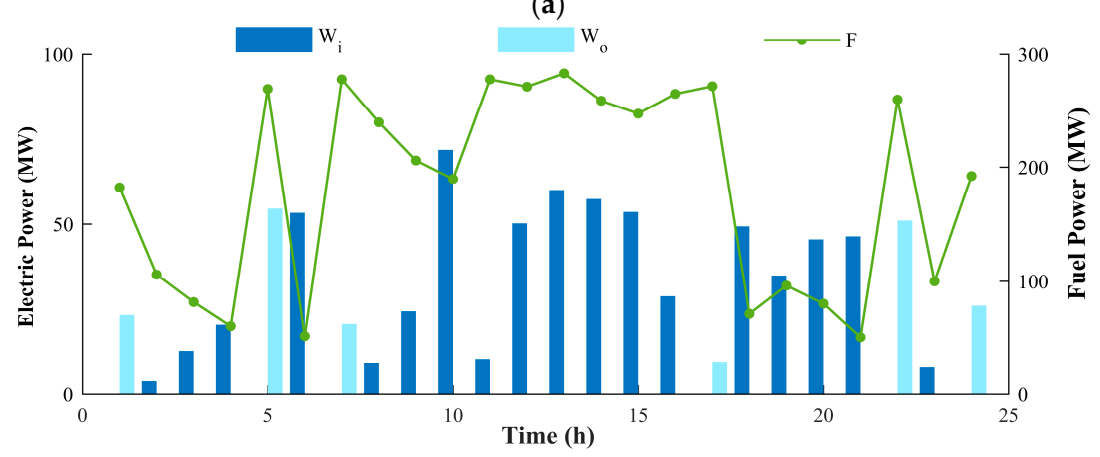

(b)

Figure 9. Dispatch result in Case 2. (a) Outputs of conventional generators and the wind turbine. (b) Input and output of the CCHP plan.

In Figure 10, the P2H/G2P plant operates in P2H mode at 3:00, 7:00-8:00, 15:00, 17:00, 20:00-21:00 and 23:00. Among them, at 3:00 and 15:00, the wind power is abundant, though the conventional generators' outputs are relatively low, the total power supply is enough for the electric demand and $\mathrm{P} 2 \mathrm{H}$ process; At 7:00, 17:00, the electric demands reach peaks, but the wind power and generator outputs peak as well, extra power are then stored in hydrogen tank for the G2P process in the following hours. The P2H/G2P plant operates in G2P mode at 1:00, 4:00, 9:00, 16:00, 18:00, and 22:00. At 1:00, 4:00, and 22:00, the outputs of generators are relatively low; at 9:00, 16:00, and 18:00, electric load reach peaks, while the generators' outputs and wind turbine outputs are relatively low. Electricity that are pre-stored in hydrogen tank then released to cope with the power shortage. 

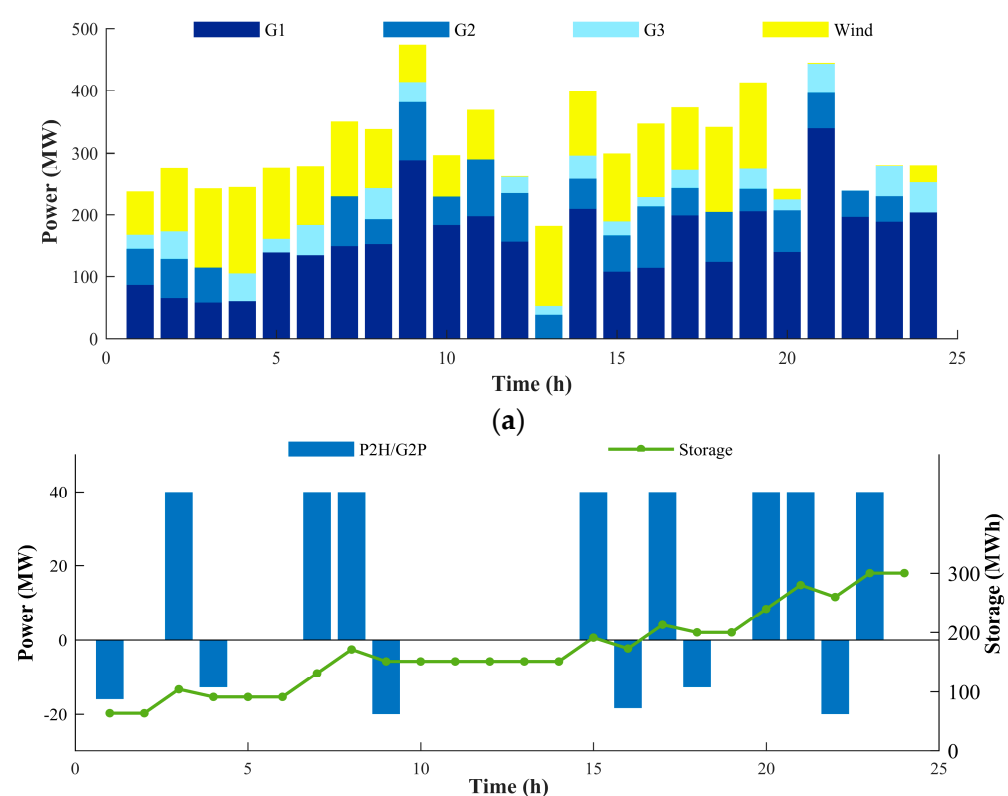

(b)

Figure 10. Dispatch result in Case 3. (a) Outputs of conventional generators and the wind turbine. (b) Output of the $\mathrm{P} 2 \mathrm{H} / \mathrm{G} 2 \mathrm{P}$ plant.

In Figure 11, at 5:00, 8:00, and 11:00, the electric demand is high while the power supply is relatively low, thus the increase in price could effectively decrease the EV charging loads in these periods. At 3:00 and 9:00, the power supply is abundant while the electric load is relatively low, thus the decrease in charging price could encourage consumers' charging behaviors in these periods, which not only saves them more money, but also alleviate the power congestion. So are at 7:00, 12:00, and 15:00, in these periods, though the electric demands are high, there is still a lot of power left. TOU pricing scheme is helpful in guiding EV users to make better charging plans that both benefit themselves and the energy system.

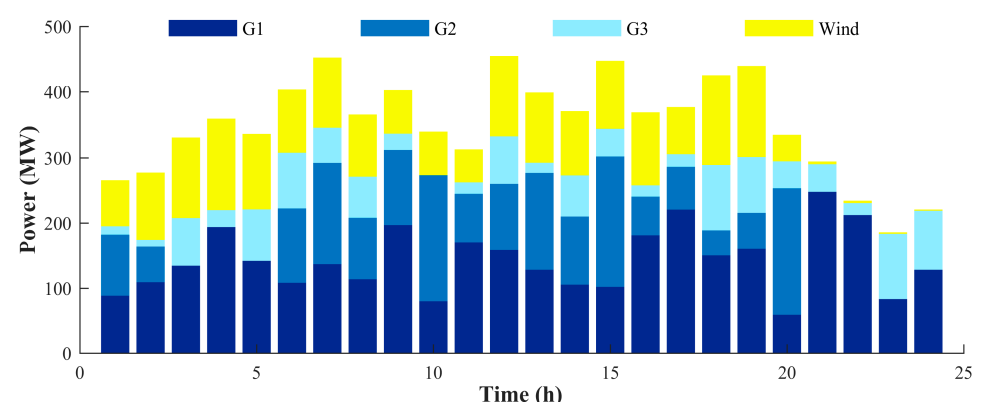

(a)

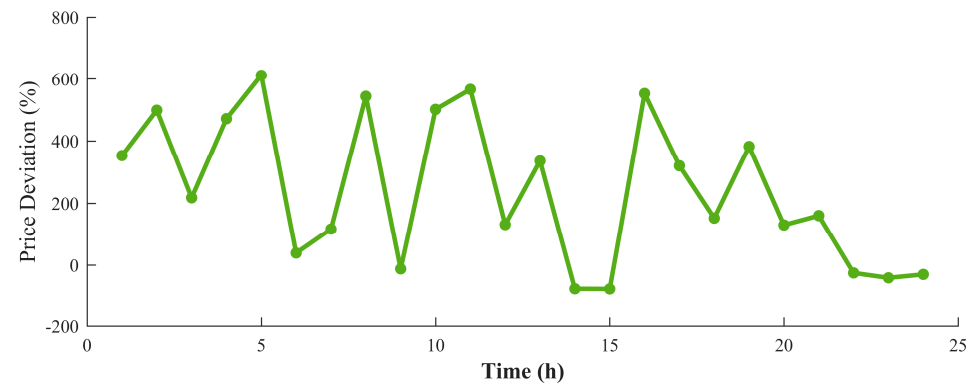

(b)

Figure 11. Dispatch result in Case 4. (a) Outputs of conventional generators and the wind turbine. (b) Price deviation for EV charging. 
Figure 12 shows the obtained dispatch schemes for Case 5 and Case 6. Figure 13 gives the RES utilization rates of the six obtained dispatch strategies, and their corresponding economic and energy saving performances as well.

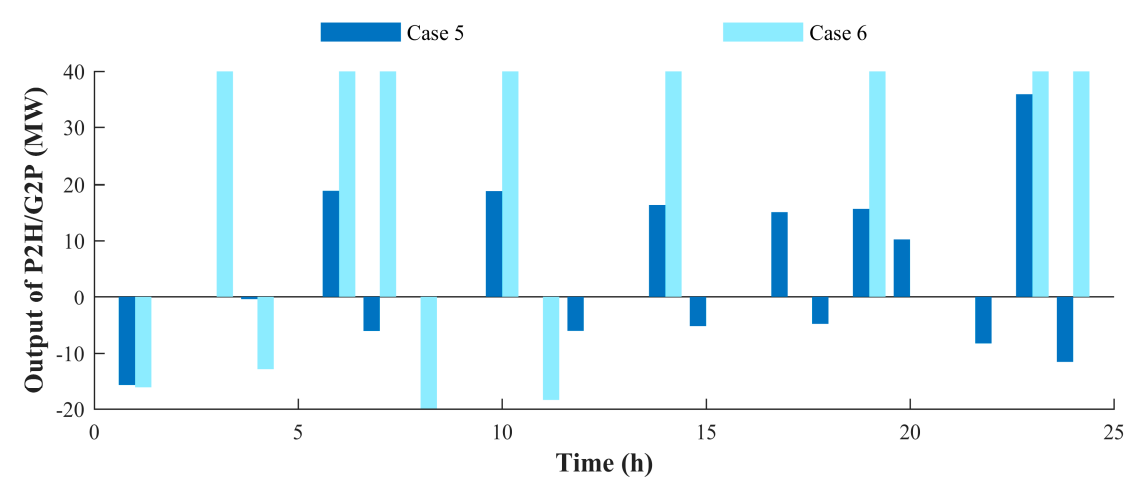

(a)

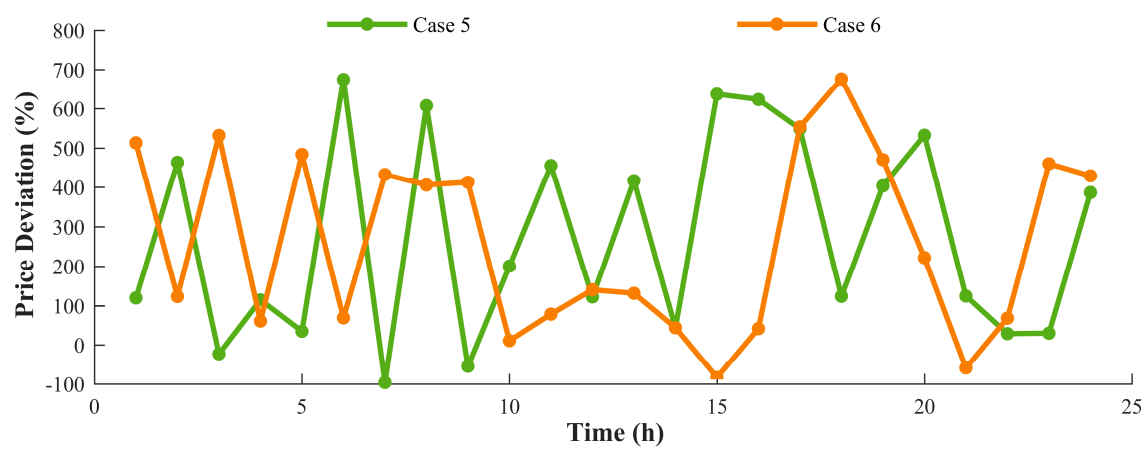

(b)

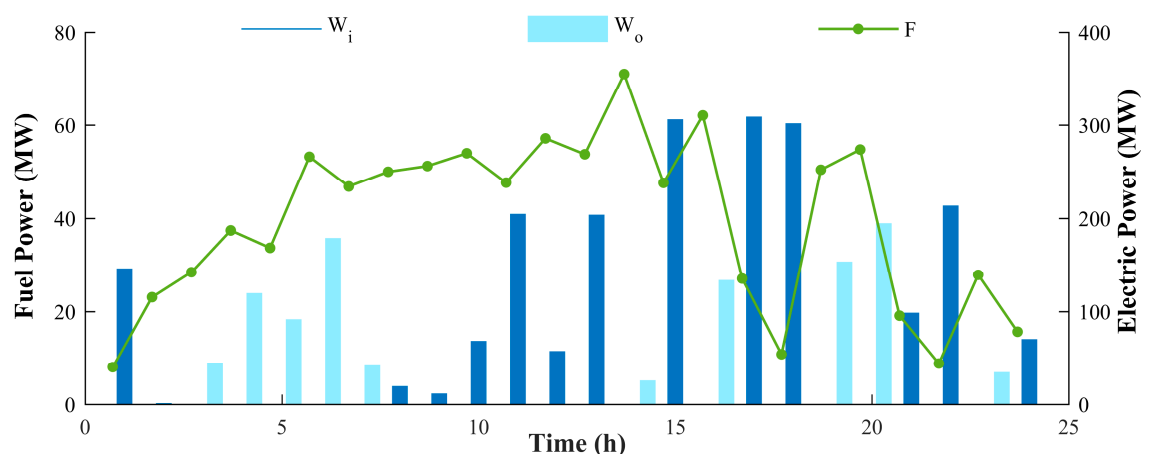

(c)

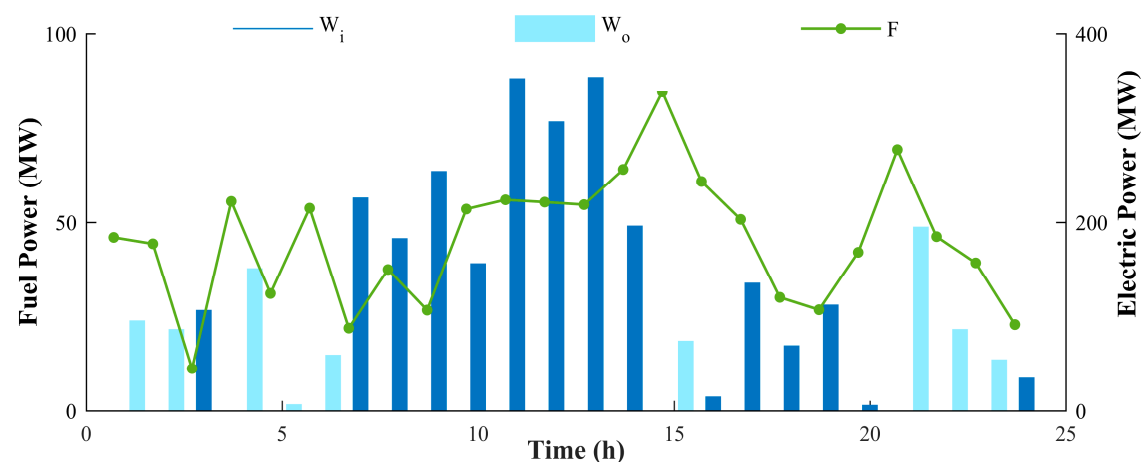

(d)

Figure 12. Dispatch result in Case 5 and Case 6. (a) Outputs of conventional generators and the wind turbine. (b) Price deviation for EV charging. (c) Input and output of CCHP plant in Case 5. (d) Input and output of CCHP plant in Case 6. 
In Figure 13, the wind power utilization rate in Case 6 is the highest, and the wind power utilization rate in Case 5, where three ME applications are all employed, is only slightly higher than in Case 1, where no ME application is deployed, while much lower than in Case 2-4, where only one application is deployed. Compare Case 5 and Case 6, the RES utilization gap is caused by the different dispatch schemes, as shown in Figure 12, which implies that:

1. The accommodating effects of the CCHP, $22 \mathrm{H} / \mathrm{G} 2 \mathrm{P}$, and demand response of EVs are remarkable, the RES utilization rate raises from $2.6 \%$, to $90.73 \%, 91.48 \%$, and $91.77 \%$. With all the three ME applications, even more RES could be adopted, a $93.14 \%$ RES utilization rate gain is achieved in Case 6.

2. However, without a comprehensive energy management method, ME may not function in a coordinate way, as shown in Figure 5, thus fail to improve the utilization of the RES, and even worsen other performances of the MES.

The other two performances in Figure 13 shows the similar patterns, the operation performance in Case 6 is superior in all the three concerned aspects, while the operation performance in Case 5 is far lower, and even lower than those in Case 2-4, where each of the ME applications functions separately. Compare Case 2-6 with Case 1, the RES utilization rate in each case have respectively increased by $88.13 \%, 88.87 \%, 89.17 \%, 33.55 \%$, and $90.54 \%$. As to the energy saving performance (ESP), $\mathrm{ESP}_{6}$ is the highest, while $\mathrm{ESP}_{3}$ is the second lowest, only higher than $\mathrm{ESP}_{1}$. It is because the $\mathrm{P} 2 \mathrm{H}$ and G2P processes involve multiple times of energy conversions, which will inevitably lead to energy loss. As to the economy, profit ${ }_{6}$ is the highest, and profit ${ }_{3}$ is the second, which owes both to the TOU pricing scheme and to higher wind power utilization rate.

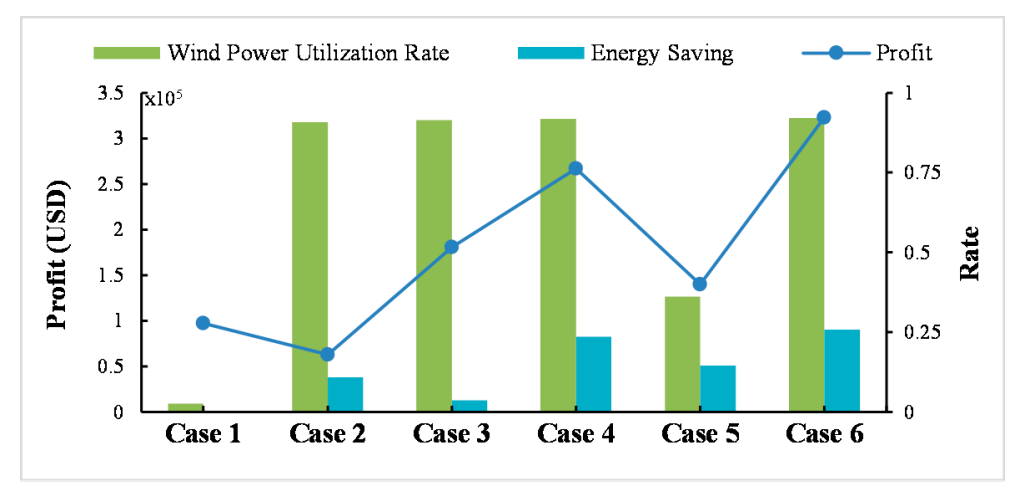

Figure 13. Performance of the dispatch schemes in Case 1-6.

With the six single objective optimization problems in Case A, we may safely arrive at the conclusion that though the ME applications can greatly enhance the MES's ability in accommodating RES, its realization counts on a comprehensive energy management method to coordinate their orderly operation. Otherwise, they may function uncoordinatedly, which not only fails to raise the RES utilization, but also degrade the operation performance of the MES, such as greatly increasing the operation cost.

\subsection{Case B}

In this Case, the proposed optimal energy management method is tested on a modified IEEE 10-generator-39-bus system case, as illustrated in Figure 14. Moreover, besides the RES utilization rate, the profit and energy saving performance of the MES are also considered as two objectives of the optimization problem. In Figure 14, the generator on Bus 34 is a wind turbine, and Bus 23, 33, and 36 are respectively connected with an EV charging facility, a CCHP plant, and a P2H/G2P plant. The detailed parameters of these ME applications are the same as in Case A, so are the ME load profile and the forecasted wind power. 


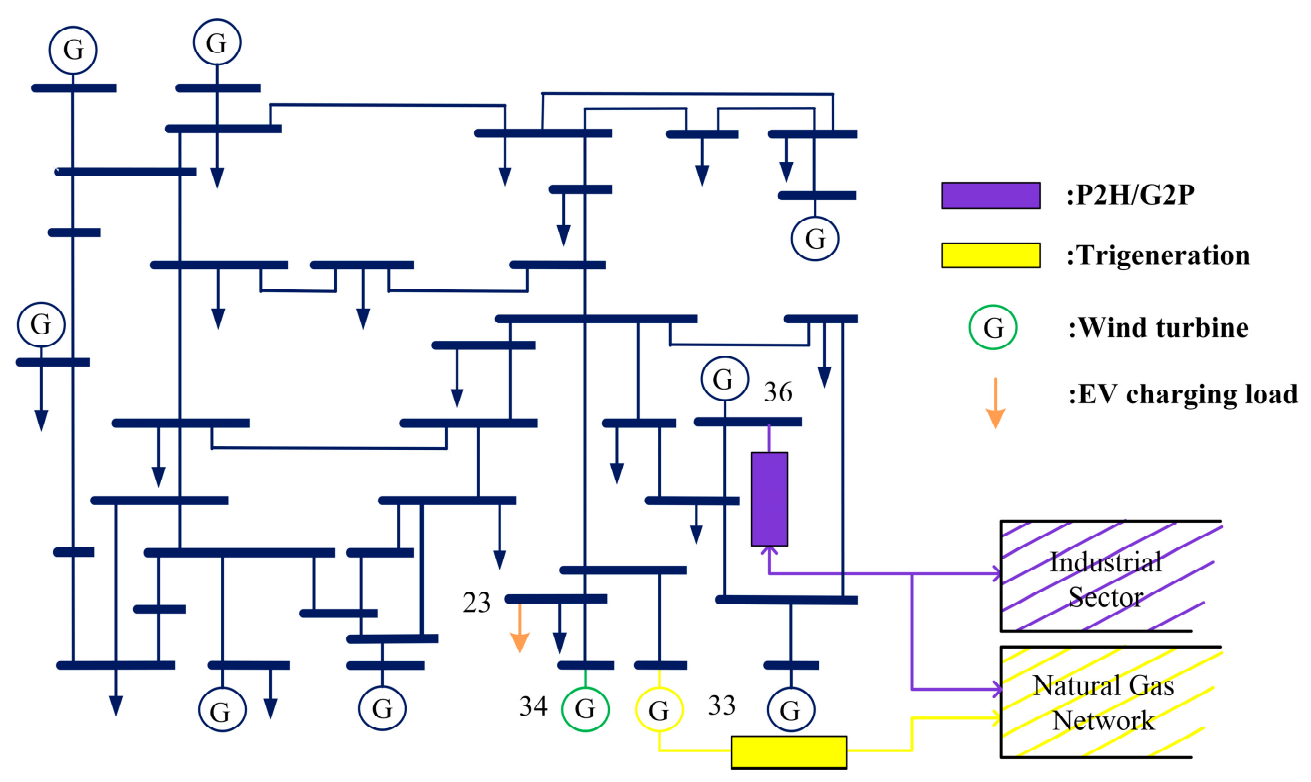

Figure 14. The diagram of the modified IEEE 39-bus case.

Three scenarios are considered below:

(1) Scenario 1: No ME applications are online;

(2) Scenario 2: All the ME applications are online, while without energy management;

(3) Scenario 3: All the ME applications are online with the proposed energy management method.

Figure 15 shows the performances of dispatch schemes for the three scenarios. In the objective space illustrated in Figure 15, $x$-axis represents the profit, $y$-axis represents the RES utilization rate, and $z$-axis represents the energy saving performance. The dispatch results in Scenario 1 are represented by blue dots, the dispatch results in Scenario 2 are represented by blue dots, and the dispatch results in Scenario 3 are represented by red dots. Each dot represent an energy dispatch scheme for the $\mathrm{ME}$ system, and all of which consist of the Pareto front of the proposed optimization method.

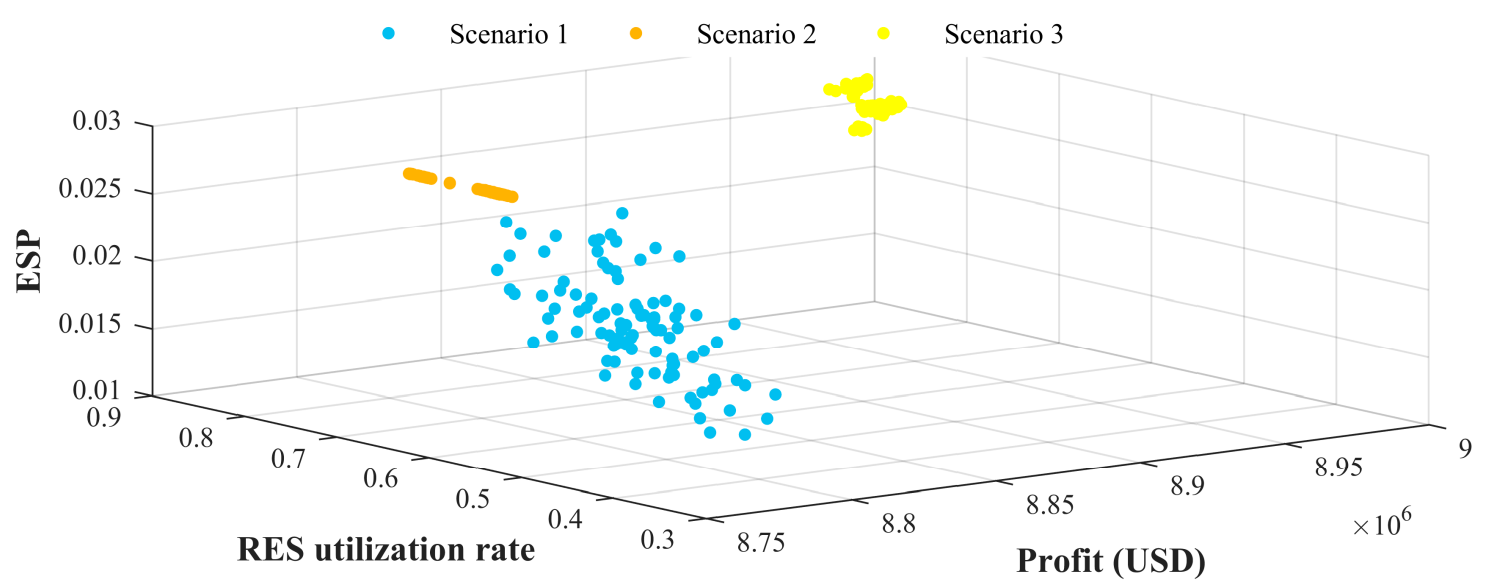

Figure 15. Optimization result of Case B.

In the objective space shown in Figure 15, the orange dots are located on the top left of the scattered blue dots. Though the space where the blue dots locate and the space where the orange dots locate overlap a little, the orange dots still outperform most of blue dots. Specifically, profit ranges $_{\text {rang }}$ from $8.7958 \times 10^{6}$ to $8.7959 \times 10^{6}$, while Profit 2 ranges from $8.75 \times 10^{6}$ to $8.83 \times 10^{6}$; RES $_{1}$ ranges from $65.33 \%$ to $76.56 \%$, while $\mathrm{RES}_{2}$ ranges from $35 \%$ to $66 \%$; $\mathrm{ESP}_{1}$ ranges from $2.72 \%$ to $2.73 \%$, while $\mathrm{ESP}_{2}$ 
ranges from $1.47 \%$ to $2.53 \%$. It indicates that though the dispatch results for Scenario 1 and the dispatch results for Scenario 2 share some performance spaces in terms of profit and RES utilization rate, the dispatch schemes for Scenario 1 are still superior than most of the dispatch schemes for Scenario 2. It suggests that without a comprehensive energy management method, ME applications are more likely to harm the operation performance of the MES rather than improve it.

The yellow dots concentrate at the top corner. It is apparent that the dispatch results in Scenario 3 are far better than those for both Scenario 1 and Scenario 2 in all the three concerned aspects. Profit 3 ranges from $8.95 \times 10^{6}$ to $8.98 \times 10^{6} ; \mathrm{RES}_{3}$ ranges from $80.58 \%$ to $80.79 \%$; $\mathrm{ESP}_{3}$ ranges from $2.39 \%$ to $2.88 \%$. On average, the profit, RES utilization rate, and energy saving performance increase by $19.91 \%, 59.77 \%$ and $31.75 \%$, respectively. Under the guidance of the proposed energy management method, all the three ME applications could operate in coordinate ways and greatly contribute to the performance improvement of the MES. The number of optimal dispatch results depends on the preset population size. Different results have different advantages, and the MES operators could select their ideal dispatch result according to their preferences.

Due to the limitation of paper length, we took one out of the 100 optimized results for Scenario 3 for illustration purposes. The EV charging price is illustrated in Figure 16a; the EDF, input and output of the CCHP plant are illustrated in Figure 16b,c respectively; the input and output of the P2H/G2P plant are illustrate in Figure 16d.

With Case B, we may clearly see that the proposed optimal energy management method effectively facilitates the coordinated operation of ME applications, and contributes to the significant improvement of the profits, RES utilization, and energy saving performance of the MES.

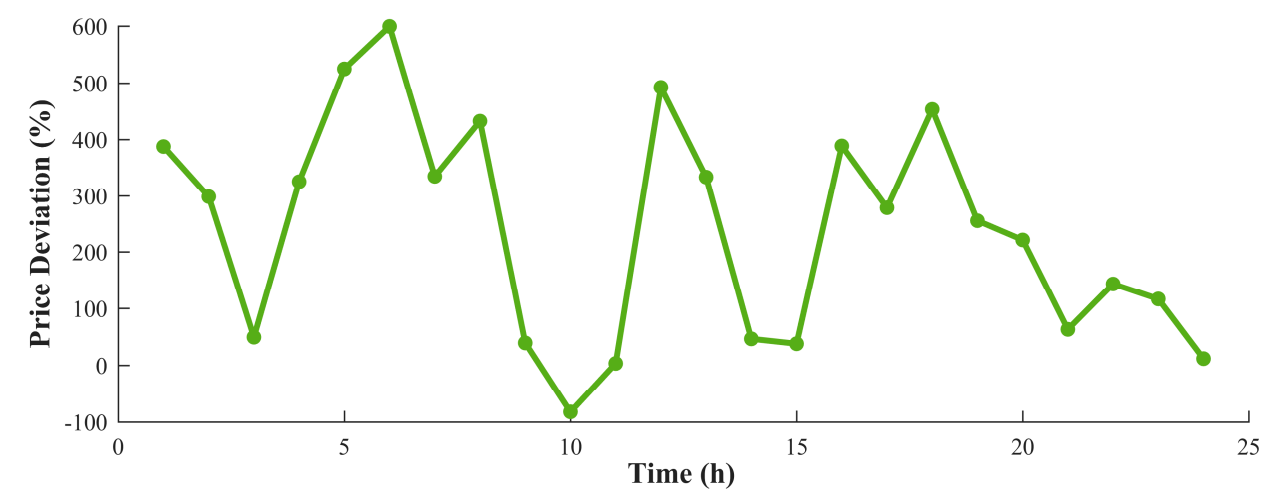

(a)

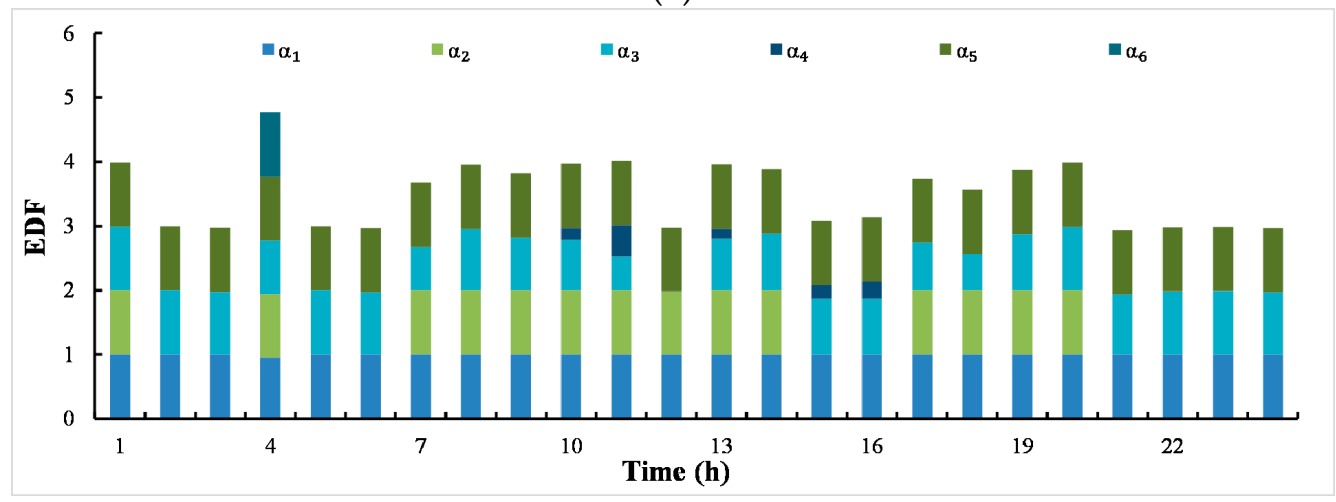

(b)

Figure 16. Cont. 


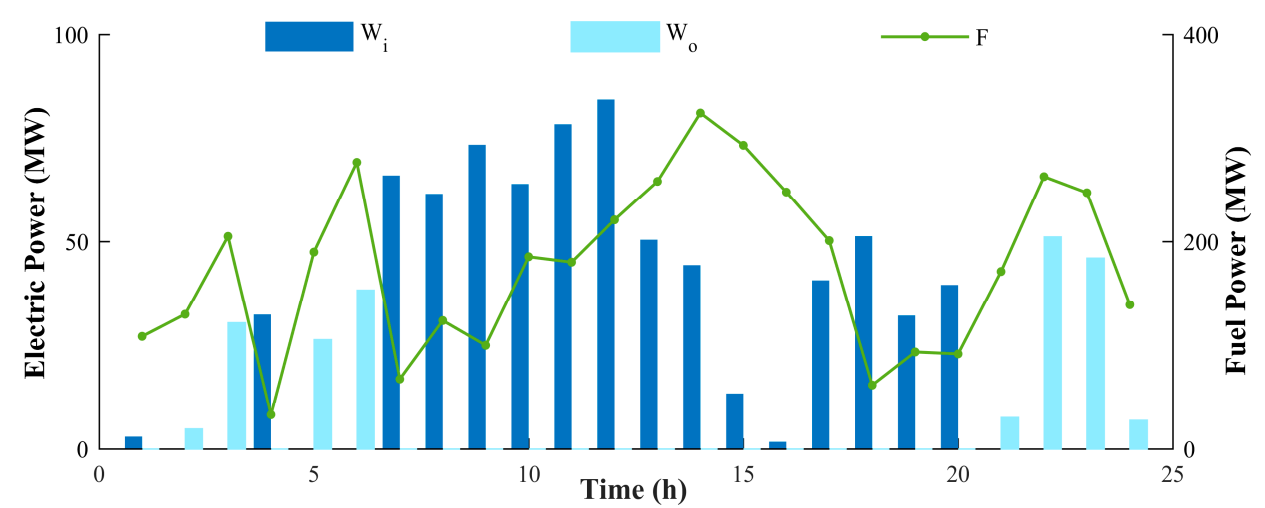

(c)

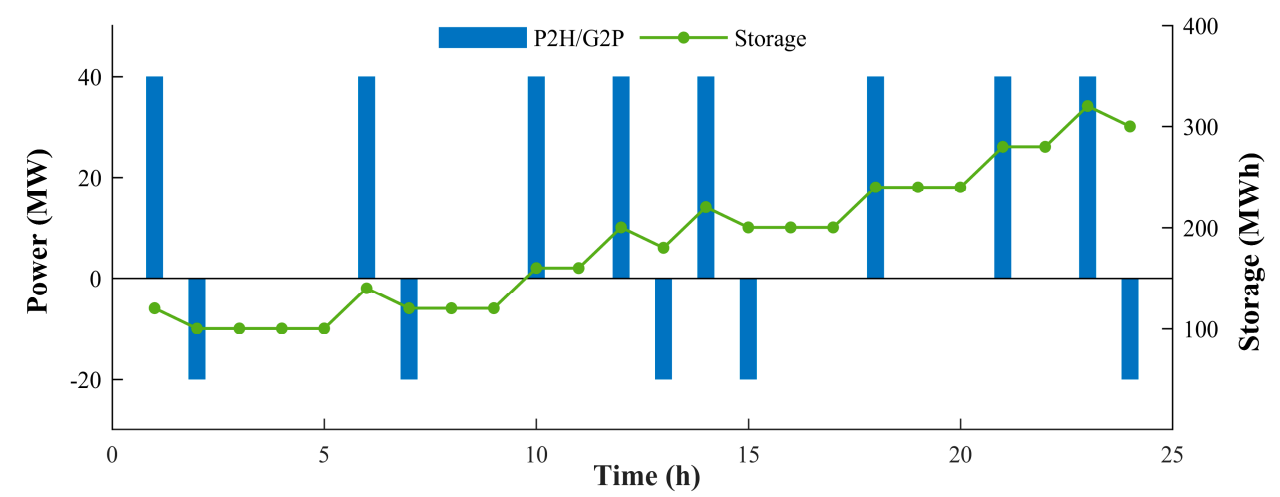

(d)

Figure 16. The detailed optimized dispatch result. (a) Deviation of EV charging price. (b) EDF of the CCHP plant. (c) Input and output of the CCHP plant. (d) The dispatch result of P2H/G2P plant.

\section{Conclusions}

In this work, a novel optimal energy management framework for the MES with multiple ME applications is presented, aiming at facilitating the coordinated operation of ME applications and improving the economic benefits, the ability in accommodating RES, and energy saving performance of the MES at the same time. In particular, the energy management models of CCHP plants, P2H/G2P plants, and the demand side management of the EV charging loads are integrated in the holistic energy management model of the MES. It will shed some lights on energy management studies of a system with multiple types of applications that have different operation mechanisms, such as a MES that is deployed with multiple types of ME applications, especially on facilitating their coordinated operation and promoting the operation performance of the entire system.

Author Contributions: Conceptualization, Y.W. and K.Z.; methodology, Y.W. and C.Z.; writing—original draft preparation, Y.W. and H.C.; writing-review and editing, Y.W., K.Z., H.C. and C.Z.

Funding: This research received no external funding.

Conflicts of Interest: The authors declare no conflict of interest.

\section{Nomenclature}

A. CCHP plant
$F_{\mathrm{i}}, F_{\mathrm{O}}$
$W_{\mathrm{i}}, W_{\mathrm{o}}$
$Q_{\mathrm{i}}, Q_{\mathrm{o}}$
$\boldsymbol{R}_{\mathrm{i}}, R_{\mathrm{o}}$
$H$

A. CCHP plant

$W_{\mathrm{i},}, W_{0}$

$Q_{\mathrm{i}}, Q_{\mathrm{o}}$

H

Fuel thermal energy input/output (MW)

Electricity input/output (MW)

Heat input/output (MW)

Cooling power input/output (MW)

Efficiency matrix of CCHP plant 
$\eta_{\mathrm{FF}}, \eta_{\mathrm{FW}}, \eta_{\mathrm{FQ}}, \eta_{\mathrm{FR}}, \eta_{\mathrm{WF}}, \eta_{\mathrm{WW}}, \eta_{\mathrm{WQ}}, \eta_{\mathrm{WR}}$ $\eta_{\mathrm{QF}}, \eta_{\mathrm{QW}}, \eta_{\mathrm{QQ}}, \eta_{\mathrm{QR}}, \eta_{\mathrm{RF}}, \eta_{\mathrm{RW}}, \eta_{\mathrm{RQ}}, \eta_{\mathrm{RR}}$ $\alpha$

$\eta_{\mathrm{W}}, \eta_{\mathrm{Q}}$

$\eta_{\mathrm{t}}$

$C O P_{\mathrm{Q}}, C O P_{\mathrm{R}}$

$\mu_{\mathrm{EP}}$

COP WARG

Q Dump

B. P2H/G2P plant

I

$P_{\mathrm{Hdr}}$

$\eta^{\mathrm{G} 2 \mathrm{P}}, \eta^{\mathrm{P} 2 \mathrm{H}}$

$P_{\min }^{\mathrm{G} 2 \mathrm{P}}, P_{\max }^{\mathrm{G} 2 \mathrm{P}}, P_{\min }^{\mathrm{P} 2 \mathrm{H}}, P_{\max }^{\mathrm{P} 2 \mathrm{H}}$

$H^{\text {sto }}$

$H_{\min }^{\text {sto }}, H_{\max }^{\text {sto }}$

$H^{\text {oth }}$

$H_{\max }^{\text {oth }}$

C. Demand response of EV

$D_{\text {ev,i }}$

$\rho_{\mathrm{i}}$

$\varepsilon_{\mathrm{ii}}$

$\varepsilon_{\mathrm{ij}}$

$\Delta D_{\mathrm{ev}, i}, \Delta \rho_{i}$

$D_{\text {ev,h }}, D_{\text {ev,f }}, D_{\text {ev,v }}$

$\rho_{\mathrm{h}}, \rho_{\mathrm{f}}, \rho_{\mathrm{v}}$

$k_{\mathrm{h}}, b_{\mathrm{h}}, k_{\mathrm{f}}, b_{\mathrm{f}}, k_{\mathrm{v}}, b_{\mathrm{v}}$

$\Omega_{\mathrm{H}}, \Omega_{\mathrm{F}}, \Omega_{\mathrm{V}}$

$\rho_{\mathrm{TOU}}, \rho_{0}$

D. Energy management model

V

$F_{i}$

$\boldsymbol{P}_{\mathrm{G}}$

$\boldsymbol{P}_{\mathrm{Hdr}}$

$\Omega_{\mathrm{B}}, \Omega_{\mathrm{G}}, \Omega_{\mathrm{R}}$

$\Omega_{\mathrm{Chr}}, \Omega_{\mathrm{Hdr}}, \Omega_{\mathrm{CCHP}}$

$P_{\mathrm{G}}$

$P_{\mathrm{P} 2 \mathrm{H}} / P_{\mathrm{G} 2 \mathrm{P}}$

$a, b, c$

$b_{\mathrm{P} 2 \mathrm{H}}, c_{\mathrm{P} 2 \mathrm{H}}, a_{\mathrm{G} 2 \mathrm{P}}, b_{\mathrm{G} 2 \mathrm{P}}, c_{\mathrm{G} 2 \mathrm{P}}$

D

$P_{\mathrm{Chr}}$

$\rho_{\mathrm{O}}^{\mathrm{EDS}}$

$\rho_{\mathrm{O}}^{\mathrm{EDS}}$

$\rho_{\mathrm{C}}^{\mathrm{FDU}}$

$\rho_{\mathrm{CCHP}}^{\mathrm{FDS}}$

$P_{\mathrm{R}}$

$P_{\mathrm{R} \_ \text {max }}$
Entires in $\boldsymbol{H}$ (subscripts denote the type of energy outputs and energy inputs)

EDF array of CCHP plant

Efficiency of $\mathrm{CHP}$ for electricity and heat production

Efficiency of $\mathrm{CHG}$

Coefficient of performance of EP for heat and cooling power production

The proportion of electricity input for heat production

Coefficient of performance of WARG

Dumped Heat of CCHP plant (MW)

Operation mode indicator

Output of P2H/G2P plant (MW)

Conversion efficiencies of G2P and $\mathrm{P} 2 \mathrm{H}$ processes

Lower and upper output limits of $\mathrm{P} 2 \mathrm{H} / \mathrm{G} 2 \mathrm{P}$ plants in G2P and $\mathrm{P} 2 \mathrm{H}$ processes (MW)

Storage level of $\mathrm{P} 2 \mathrm{H} / \mathrm{G} 2 \mathrm{P}$ plant $(\mathrm{MW} \cdot \mathrm{h})$

Lower and upper storage limits $(\mathrm{MW} \cdot \mathrm{h})$

Hydrogen power demand of other sectors (MW)

Upper limits of $H^{\text {oth }}(\mathrm{MW})$

Electricity consumption in period $i(\mathrm{MW})$

Electricity price in period $i(\$)$

Self-elasticity coefficient in period $i$

Cross-elasticity coefficient between period $i$ and period $j$

Electricity consumption change (MW), price change (\$) in period $i$

Electricity consumption during peak, flat and valley periods (MW)

Electricity price during peak, flat, and valley periods (\$)

Factors used to describe the linearized relationships between

electricity Consumption and price during peak, flat,

and valley periods

Peak, flat, and valley periods sets

Base electricity price array and TOU price (\$)

Decision variable vector

Objective function $i$

Output array of generators (MW)

Output array of P2H/G2P plants (MW)

Buses, generators and RES set

EV charging facilities, $\mathrm{P} 2 \mathrm{H} / \mathrm{G} 2 \mathrm{P}$ and CCHP plants set

Outputs of generators (MW)

Outputs of $\mathrm{P} 2 \mathrm{H} / \mathrm{G} 2 \mathrm{P}$ plants in P2H/G2P mode (MW)

Consumption characteristics of generators

Consumption characteristics of $\mathrm{P} 2 \mathrm{H} / \mathrm{G} 2 \mathrm{P}$ plants

Electric load (MW)

EV charging load (MW)

Selling price of electricity (\$)

TOU EV charging price (\$)

Fuel price for electricity production (\$)

Fuel price for heat and cooling power production (\$)

RES outputs (MW)

Maximal RES outputs (MW) 


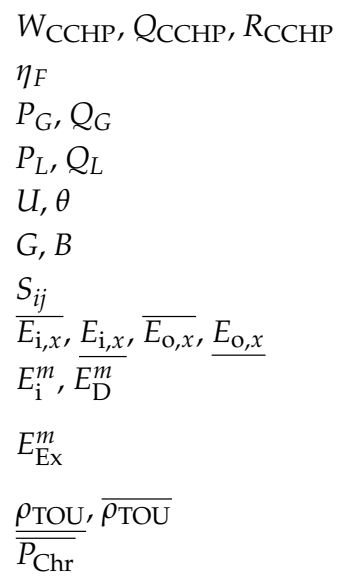

Electricity, heat, and cooling output of CCHP plants (MW)

Fuel Thermal energy rate

Active and reactive power outputs of generators (MW)

Active and reactive demands (MW)

Bus voltage magnitude and voltage angle

Conductance and reactance in admittance matrix

Apparent power between bus $i$ and bus $j$ (MVA)

Input and output limits of ME device $x$ (MW)

ME input and ME demands of the CCHP plant $m$ (MW)

ME exchange between CCHP plant $m$ and external ME distribution networks (MW)

Limits of EV charging price

Maximum EV charging load (MW)

\section{References}

1. Mancarella, P.; Andersson, G.; Peças-Lopes, J.A.; Bell, K.R.W. Modelling of integrated multi-energy systems: Drivers, requirements, and opportunities. In Proceedings of the 2016 Power Systems Computation Conference (PSCC), Genoa, Italy, 20-24 June 2016; pp. 1-22.

2. Bao, Z.; Zhou, Q.; Yang, Z.; Yang, Q.; Xu, L.; Wu, T. A Multi Time-Scale and Multi Energy-Type Coordinated Microgrid Scheduling Solution-Part I: Model and Methodology. IEEE Trans. Power Syst. 2015, 30, 2257-2266. [CrossRef]

3. Clegg, S.; Mancarella, P. Integrated Electrical and Gas Network Flexibility Assessment in Low-Carbon Multi-Energy Systems. IEEE Trans. Sustain. Energy 2016, 7, 718-731. [CrossRef]

4. Strbac, G. Integrating renewable energy to the grid optimising and securing the network: Facilitating cost effective integration of renewable energy in GB grid. In IET Seminar on Integrating Renewable Energy to the Grid: Optimising and Securing the Network; IET: London, UK, 2014; pp. 1-22.

5. Olatomiwa, L.; Mekhilef, S.; Ismail, M.S.; Moghavvemi, M. Energy management strategies in hybrid renewable energy systems: A review. Renew. Sustain. Energy Rev. 2016, 62, 821-835. [CrossRef]

6. Chen, Y.B.; Wang, Y.Z.; Ma, J. Multi-Objective Optimal Energy Management for the Integrated Electrical and Natural Gas Network with Combined Cooling, Heat and Power Plants. Energies 2018, 11, 734. [CrossRef]

7. Mancarella, P.; Chicco, G. Integrated energy and ancillary services provision in multi-energy systems. In Proceedings of the 2013 IREP Symposium Bulk Power System Dynamics and Control—IX Optimization, Security and Control of the Emerging Power Grid, Rethymno, Greece, 25-30 August 2013; pp. 1-19.

8. Zhang, R.; Jiang, T.; Li, G.; Chen, H.; Li, X.; Bai, L.; Cui, H. Day-ahead scheduling of multi-carrier energy systems with multi-type energy storages and wind power. CSEE J. Power Energy Syst. 2018, 4, 283-292. [CrossRef]

9. Ivanova, P.; Sauhats, A.; Linkevics, O. District Heating Technologies: Is It Chance for CHP Plants in Variable and Competitive Operation Conditions? IEEE Trans. Ind. Appl. 2018. [CrossRef]

10. Ban, M.F.; Yu, J.L.; Shahidehpour, M.; Yao, Y.Y. Integration of power-to-hydrogen in day-ahead security-constrained unit commitment with high wind penetration. J. Mod. Power Syst. Clean Energy 2017, 5, 337-349. [CrossRef]

11. Shao, C.; Wang, X.; Wang, X.; Du, C.; Dang, C.; Liu, S. Cooperative Dispatch of Wind Generation and Electric Vehicles with Battery Storage Capacity Constraints in SCUC. IEEE Trans. Smart Grid 2014, 5, 2219-2226. [CrossRef]

12. Siano, P. Demand response and smart grids-A survey. Renew. Sustain. Energy Rev. 2014, 30, 461-478. [CrossRef]

13. Mancarella, P. From Cogeneration to Trigeneration: Energy Planning and Evaluation in a Competitive Market Framework. Ph.D. Thesis, Politecnico di Torino, Turin, Italy, 2006.

14. Chicco, G.; Mancarella, P. Enhanced Energy Saving Performance in Composite Trigeneration Systems. In Proceedings of the 2007 IEEE Lausanne Power Tech, Lausanne, Switzerland, 1-5 July 2007; pp. 1423-1428.

15. Schiebahn, S.; Grube, T.; Robinius, M.; Tietze, V.; Kumar, B.; Stolten, D. Power to gas: Technological overview, systems analysis and economic assessment for a case study in Germany. Int. J. Hydrog. Energy 2015, 40, 4285-4294. [CrossRef]

16. Guandalini, G.; Campanari, S.; Romano, M.C. Comparison of gas turbines and power-to-gas plants for Improved Wind Park Energy dispatchability. In Proceedings of the ASME Turbo Expo 2014: Turbine Technical Conference and Exposition, Düsseldorf, Germany, 16-20 June 2014. 
17. Guandalini, G.; Campanari, S.; Romano, M.C. Power-to-gas plants and gas turbines for improved wind energy dispatchibility: Energy and economic assessment. Appl. Energy 2015, 147, 117-130. [CrossRef]

18. Zhang, X.; Shahidehpour, M.; Alabdulwahab, A.; Abusorrah, A. Optimal Expansion Planning of Energy Hub with Multiple Energy Infrastructures. IEEE Trans. Smart Grid 2015, 6, 2302-2311. [CrossRef]

19. Song, Y.H.; Yang, X.; Lu, Z.X. Integration of plug-in hybrid and electric vehicles: Experience from China. In Proceedings of the 2010 IEEE Power Engineering Society General Meeting, Providence, RI, USA, 25-29 July 2010; pp. $1-5$.

20. Ferdowsi, M. Vehicle Fleet as a distributed energy storage system for the power grid. In Proceedings of the 2009 IEEE Power Engineering Society General Meeting, Calgary, AB, Canada, 26-30 July 2009; pp. 1-2.

21. De Forest, N.; Funk, J.; Lorimer, A.; Ur, B.; Sidhu, I.; Kaminsky, P.; Tenderich, B. Impact of Widespread Electric Vehicle Adoption on the Electrical Utility Business-Threats and Opportunities. University of California: Berkeley. Available online: http:/ / cet.berkeley.edu/dl/Utilities_Final_8-31-09.pdf (accessed on 28 September 2018).

22. Yu, R.; Zhong, W.; Xie, S.; Yuen, C.; Gjessing, S.; Zhang, Y. Balancing Power Demand Through EV Mobility in Vehicle-to-Grid Mobile Energy Networks. IEEE Trans. Ind. Inform. 2016, 12, 79-90. [CrossRef]

23. Sarker, M.R.; Ortega-Vazquez, M.A.; Kirschen, D.S. Optimal Coordination and Scheduling of Demand Response via Monetary Incentives. IEEE Trans. Smart Grid 2015, 6, 1341-1352. [CrossRef]

24. Xu, Z.W.; Hu, Z.C.; Song, Y.H.; Zhang, H.C.; Chen, X.S. Coordinated Charging Strategy for PEV Charging Stations Based on Dynamic Time-of-use Tariffs. Proc. CSEE 2014, 34, 3638-3646.

25. Chen, C.Y.; Hu, B.; Xie, K.G.; Wan, L.Y.; Xiang, B. A Peak-Valley TOU Price Model Considering Power System Reliability and Power Purchase Risk. Power Syst. Technol. 2014, 38, 2141-2148.

26. Deb, K.; Pratap, A.; Agarwal, S.; Meyarivan, T. A fast and elitist multi-objective genetic algorithm: NSGA-II. IEEE Trans. Evol. Comput. 2002, 6, 182-197. [CrossRef]

27. Harvey, L.D.D. A Handbook on Low-Energy Buildings and District-Energy Systems: Fundamentals, Techniques and Examples; Routledge: London, UK, 2012; ISBN 978-184407-243-9.

28. Kirschen, D.S.; Strbac, G.; Cumperayot, P.; Mendes, D.D. Factoring the elasticity of demand in electricity prices. IEEE Trans. Power Syst. 2000, 15, 612-617. [CrossRef]

29. Safdarian, A.; Fotuhi-Firuzabad, M.; Lehtonen, M. A Medium-Term Decision Model for DisCos: Forward Contracting and TOU Pricing. IEEE Trans. Power Syst. 2015, 30, 1143-1154. [CrossRef]

30. Wood, A.J.; Wollenberg, B.F.; Wiley, J. Power Generation, Operation, and Control; Wiley-Interscience: Hoboken, NJ, USA, 1996. 